\title{
Monitoreo energético experimental de vivienda unifamiliar compacta en un clima templado frio de Argentina
}

\author{
Experimental energy monitoring of compact dwellings in \\ a cold temperate climate in Argentina
}

\section{Celina Filippín \\ Eugenia Sipowicz \\ Silvana Flores Larsen}

\section{Resumen}

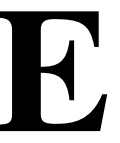

n el presente trabajo se estudia el comportamiento térmico-energético de viviendas compactas entre medianeras implantadas en barrios residenciales de baja densidad en la ciudad de Santa Rosa, La Pampa Argentina (latitud: $36^{\circ} 27^{\prime} \mathrm{S}$ y longitud: $64^{\circ} 27^{\prime} \mathrm{W}$ ). Los objetivos son evaluar la temperatura interior y las condiciones de confort en invierno a través del monitoreo experimental y analizar el consumo histórico de gas natural en calefacción. Los resultados muestran que las viviendas compactas entre medianeras tienen un 50\% menos de consumo de gas natural que la vivienda social unifamiliar en la misma región en estudio. El panorama energético de Argentina, la posibilidad de revisar Normativas y Códigos de Edificación, la tendencia del crecimiento de la construcción de viviendas en la región en estudio, el proceso de etiquetado de la edificación, entre otros aspectos, ameritan un análisis de la información de las características del stock de las edificios y de su performance energética. La creación de un protocolo de monitoreo armonizado de datos es imperativa.

Palabras claves: Vivienda compacta entre medianeras. Consumo de energía en calefacción. Confort térmico.

Celina Filippín Consejo Nacional de Investigaciones Científicas y Técnicas Santa Rosa - La Pampa - Argentina

Eugenia Sipowicz Consejo Nacional de Investigaciones Científicas y Técnicas Córdoba Capital - Argentina

Silvana Flores Larsen Universidad Nacional de Salta Salta - Argentina

Recebido em 22/05/13 Aceito em 18/11/13

\section{Abstract}

In this research work, the thermal-energy behaviour of compact dwellings between party walls built in low-density residential neighbourhoods in the city of Santa Rosa, La Pampa, Argentina (latitude: $36^{\circ} 27^{\prime} S$ and longitude $64^{\circ} 27^{\prime} \mathrm{W}$ ) is investigated. The objectives are to evaluate the indoor temperature and comfort conditions in winter through experimental monitoring, and to analyze the historical consumption of natural gas for heating. The results show that compact dwellings between party walls consume $50 \%$ less natural gas than single-family social houses in the same region. The Argentinian energy scenario, the possibility of revising Standards and Building Codes, the trend of growth in housing construction in the region under study, the building labelling process, among other things, merit a data analysis of the stock of buildings and their energy performance. The creation of a harmonized monitoring protocol data is imperative.

Keywords: Compact dwellings between party walls. Heating energy consumption. Thermal comfort. 


\section{Introducción}

En nuestras sociedades dependientes del petróleo, la energía consumida es una parte muy importante de la huella ecológica y es responsable del $80 \%$ de las emisiones de $\mathrm{CO}_{2}$. La cuestión energética está íntimamente relacionada con la crisis climática y ambiental. El IPCC, organismo científico de Naciones Unidas sobre cambio climático, señaló que, a partir de un calentamiento global del planeta con respecto a los niveles preindustriales, las consecuencias del cambio climático serán imprevisibles. Para evitar el aumento de la temperatura media recomienda, que la concentración de gases de efecto invernadero en la atmósfera se estabilice en un nivel inferior a las 450 partes por millón de $\mathrm{CO}_{2}$ equivalente. El mundo se debe dirigir a una economía baja en carbono, cuyos productos y servicios reduzcan considerablemente las emisiones. Es necesario transformar el modelo energético actual y buena parte del conjunto del modelo productivo y de consumo. En el sector de la edificación la optimización del uso de la radiación solar, el aislamiento térmico, el control de la ventilación y el intercambio de calor permitirían reducir la demanda energética para climatización a valores próximos a los $10-15 \mathrm{kWh} / \mathrm{m}^{2}$. De acuerdo al informe del Programa Cambio Global España 2020/50 (CENTRO..., 2010) se puede aspirar a una fuerte descarbonización del sector de la edificación con su re-configuración a partir de la rehabilitación bioclimática del tejido edificado de las ciudades. Anteriormente, el Proyecto Final del (IPCC, 2007) consideró que, las estrategias de diseño de los edificios energéticamente eficientes y de alta calidad ambiental interior, debían estar orientadas a la reducción de las cargas de calefacción y enfriamiento, a la selección de sistemas que permitiera un uso más efectivo de los recursos energéticos y a un uso eficiente de los equipamientos.

Por qué se debe prestar atención a la calidad del ambiente interior de los edificios durante la etapa de diseño? Entre otros aspectos, porque proporcionan un entorno de vida y de trabajo a los seres humanos y la gente pasa más del $80 \%$ de su vida en el interior de los edificios. (RATTI; RAYDAN; STEAMERS, 2003), sostienen que el edificio es una entidad integrada estructural, tanto desde el punto de vista funcional como ambiental. El mejoramiento de su performance energética requiere de un estudio detallado y una simulación de su comportamiento, sin dejar de considerar los fenómenos que ocurren, entre otros, a escala urbana. (PEETERS et al., 2009), consideran que en los edificios residenciales las condiciones internas están lejos de tener el estado de equilibrio: tanto el nivel de actividad y el tipo de ropa pueden variar dentro de plazos de tiempo pequeños, pueden fluctuar las ganancias internas y los aportes de energía afectando rápidamente a la temperatura interior. La variación en la ocupación tendrá influencia, entre otros, en la tasa de ventilación requerida. (DIXIT et al., 2010), afirman que es urgente la revisión y modificación de las prácticas actuales de la construcción en cuanto al diseño, técnicas y tecnologías de fabricación para optimizar el consumo de energía. (LIU; ZHANG; ZHAI, 2010), concluyen que, para crear un edificio de bajo consumo de energía se necesitan nuevos conocimientos y el desarrollo de nuevos materiales, tecnologías y sistemas. La eficiencia energética, sin embargo, depende tanto de estas tecnologías como también de las opciones del usuario y de las políticas que también afectan a la toma de decisiones (ALCOTT; HUNT; MULLAINATHAN SENDHIL, 2010).

La visión premonitoria del arquitecto Buckminster Fuller, sobre la finitud de los recursos mundiales se remonta a sus notas de finales de 1920 (BEHLING; BEHLING, 2002). Fue recién en 1973, con altos precios del petróleo, cuando las estrategias de conservación de energía irrumpieron en la agenda ambiental. El sector edilicio está particularmente bajo presión: aproximadamente la mitad de los recursos mundiales son empleados para acondicionar el ambiente interior. El sector de la construcción es uno de los principales protagonistas de los problemas ambientales debido a la explotación de los recursos no renovables, el uso del suelo y el consumo de energía durante el ciclo de vida completo de un edificio. (ÜRGEVORSATZ; NOVIKOVA, 2006), afirman que durante el año 2004 sólo los edificios agotaron casi el $37 \%$ de la energía del mundo y se prevé esta cifra alcanzara el $42 \%$ en 2030. En Europa, y en el año 2000 , el $45 \%$ de la energía producida se usó en el sector edilicio y el $50 \%$ de la polución fue causada por el mismo sector (BALLARINI; CORRADO , 2009).

En la República Argentina, y de acuerdo al Inventario de gases de efecto invernadero - Año 2000, el $91 \%$ de las emisiones de $\mathrm{CO}_{2}$ del sector energía correspondieron a la quema de combustibles, el 9\% restante, a las emisiones fugitivas. Las industrias de la energía fueron responsables del $30 \%$ de las emisiones, seguidas por el transporte de cargas con el $18,2 \%$ y el residencial con el 14,4\%, entre otros. Hubo un incremento de las emisiones del $28 \%$ entre 1990 y 2000 con una tasa anual acumulada del $2,5 \%$. Los dos sectores que más aumentaron su participación 
en el 'Consumo Neto Total' de energía fueron: el residencial (que pasó del 13,6\% de participación en el CFT en 1970 al $19,4 \%$ en el 2003) y el comercial y público $(2,6 \%$ en 1970 y $6,7 \%$ en el 2003). Estos consumos, están directamente vinculados al nivel de satisfacción de las necesidades energéticas de los hogares y de los servicios, y se han incrementado, en gran medida, por la penetración del gas distribuido que no sólo ha sustituido otras fuentes sino que ha aumentado los consumos específicos en los usos calóricos (cocción, calentamiento de agua y calefacción). En cuanto a la participación de los combustibles en las emisiones en términos de $\mathrm{CO}_{2}$, y en el sector residencial, el gas natural absorbe un $81.1 \%$ (FUNDACIÓN..., 2005).

El uso de las energías no convencionales, el panorama energético de Argentina, la posibilidad de revisar Normativas y Códigos de Edificación, el incremento en la compra de equipos de aire acondicionado (incremento del $12.6 \%$ en el año 2008, según el Instituto Nacional de Estadística y Censos), la tendencia del crecimiento de la construcción de viviendas (INSTITUTO..., 2006), entre otros aspectos, motivaron a distintos autores ${ }^{1}$ a evaluar edificios residenciales para analizar el comportamiento térmico-energético, las condiciones de confort, el consumo de energía, el comportamiento del usuario.

En la región en estudio, las localidades de la provincia de La Pampa son importadoras de gas natural y energía eléctrica. La red eléctrica está conectada al Sistema Interconectado Nacional. En la ciudad de Santa Rosa, capital de la provincia, el consumo residencial de energía eléctrica representa el $87.2 \%$ del total facturado y la energía consumida por usuario, se incrementó en un $5.6 \%$ en el período 2008-2009 (CAMUZZI..., 2009). De acuerdo con (RATTI; BAKER; STEAMERS, 2005) la performance energética depende de la geometría urbana, el diseño del propio edificio, la eficiencia de los sistemas y el comportamiento del ocupante.

\section{Objetivo}

En este marco el objetivo general del presente trabajo es conocer el comportamiento térmicoenergético y las condiciones de confort y/o disconfort de viviendas compactas, másicas y construidas entre medianeras. Tipología que

${ }^{1}$ Rosenfeld e Czajkowski, 1992; Re e Blasco Lucas, 2008; Salvetti, Czajkowski e Gómez, 2009, 2010; Molas et al., 2008; Filippín et al., 2005; Filippín e Flores Larsen, 2009; Filippín, Flores Larsen e Mercado, 2011; Hernández, 2006; Mitchell e Acosta, 2009; Mercado et al., 2008; Viegas, 2010; Ganem, Esteves e Coch, 2006; Sulaiman, Blasco Lucas e Filippín, 2009; y González et al., 2007. predomina en distintos barrios de la ciudad de Santa Rosa (Figura 1). El estudio tiene como objetivos específicos:

(a) monitorear térmica y energéticamente durante invierno, viviendas de distinta orientación con igual tipología y tecnología;

(b) analizar estadísticamente el consumo de gas natural y su coeficiente de variación en el período 2000-2009;

(c) analizar el consumo de gas natural en invierno de 2010; y

(d) estimar el comportamiento térmico-energético de un mosaico urbano a partir de viviendas monitoreadas.

\section{Caracterización climática de la región en estudio: Santa Rosa, La Pampa}

Las condiciones climatológicas de una localidad condicionan la forma de vida de sus habitantes. Por ello, el diseño de los espacios supone una respuesta a las condiciones climatológicas adversas, facilitando la adaptación del hombre al medio ambiente. El conocimiento del clima local o regional es fundamental para la toma de decisiones en un área. La provincia de La Pampa se caracteriza por poseer un clima templado frio (temperatura media anual entre $14^{\circ}$ y $16^{\circ} \mathrm{C}$ ), con gran amplitud térmica estacional, que alcanza valores generales de $16^{\circ} \mathrm{C}$. Esto refleja su carácter continental que se incrementa hacia el Oeste. La parte menos fría de la provincia se encuentra al Norte, (con una temperatura medía del mes de julio de alrededor de $8^{\circ} \mathrm{C}$ ), mientras que la más fría es la del Sur-Sud Oeste con valores cercanos a los $6^{\circ} \mathrm{C}$. Presenta temperaturas mínimas absolutas que pueden llegar a $-14^{\circ} \mathrm{C}$. En enero se registran las mayores temperaturas máximas absolutas (alrededor de $41^{\circ} \mathrm{C}$ ). La temperatura máxima anual media es de unos $40^{\circ} \mathrm{C}$, siendo la zona centro-norte la que posee los valores más altos y por lo tanto el clima más cálido de la provincia. La máxima absoluta oscila entre los $40^{\circ}$ y $45^{\circ} \mathrm{C}$. Los elementos y factores del clima de importancia en La Pampa son: temperatura, precipitación, viento, humedad atmosférica, circulación general de la atmósfera. Como factores limitantes de gran envergadura, pueden citarse las bajas precipitaciones y altas temperaturas (Caracterizacion general de la Provincia) (Figura 2).

Una clasificación macro ambiental simplificada de la provincia de La Pampa en función, de aspectos geomorfológicos, altimétricos, pluviométricos y 
Fito geográficos, divide al territorio provincial en dos regiones muy diferenciadas, el Este y el Oeste. La región Este es la región de mayor desarrollo socio-cultural y de mayor potencialidad productiva y económica (SUBSECRETARÍA..., 1994). En esta región bioambiental IIIa de la IRAM 11603
(INSTITUTO..., 1996), se encuentra la ciudad de Santa Rosa, capital de la provincia de La Pampa. Sus coordenadas geográficas son: latitud: $36^{\circ} 27^{\prime}$ y longitud: $64^{\circ} 27^{\prime}$. La altura sobre el nivel del mar es de 182 metros (Figura 2).

Figura 1 - Localización de la ciudad en estudio y vistas aérea - sectores de la ciudad con baja densidad de edificación

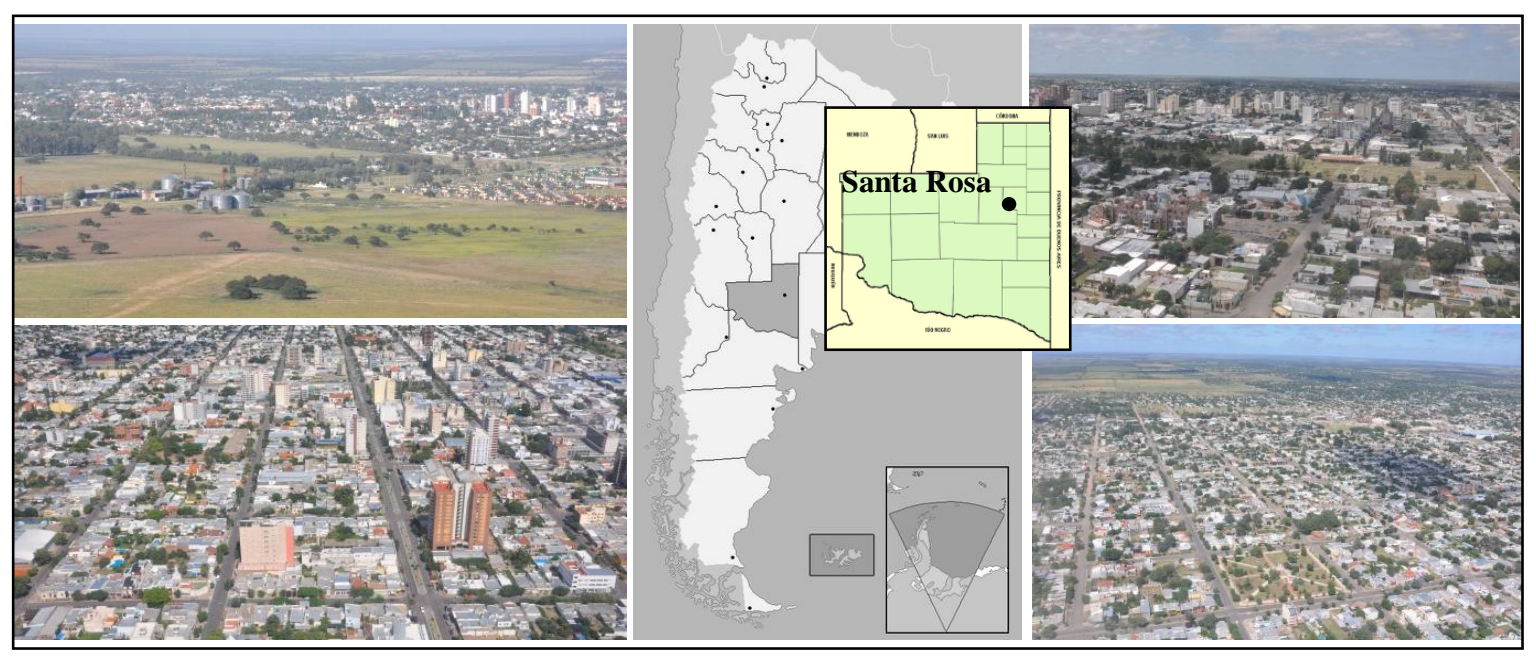

Figura 2 - Caracterización climática de la Provincia de La Pampa, y ubicación de la capital provincial Santa Rosa

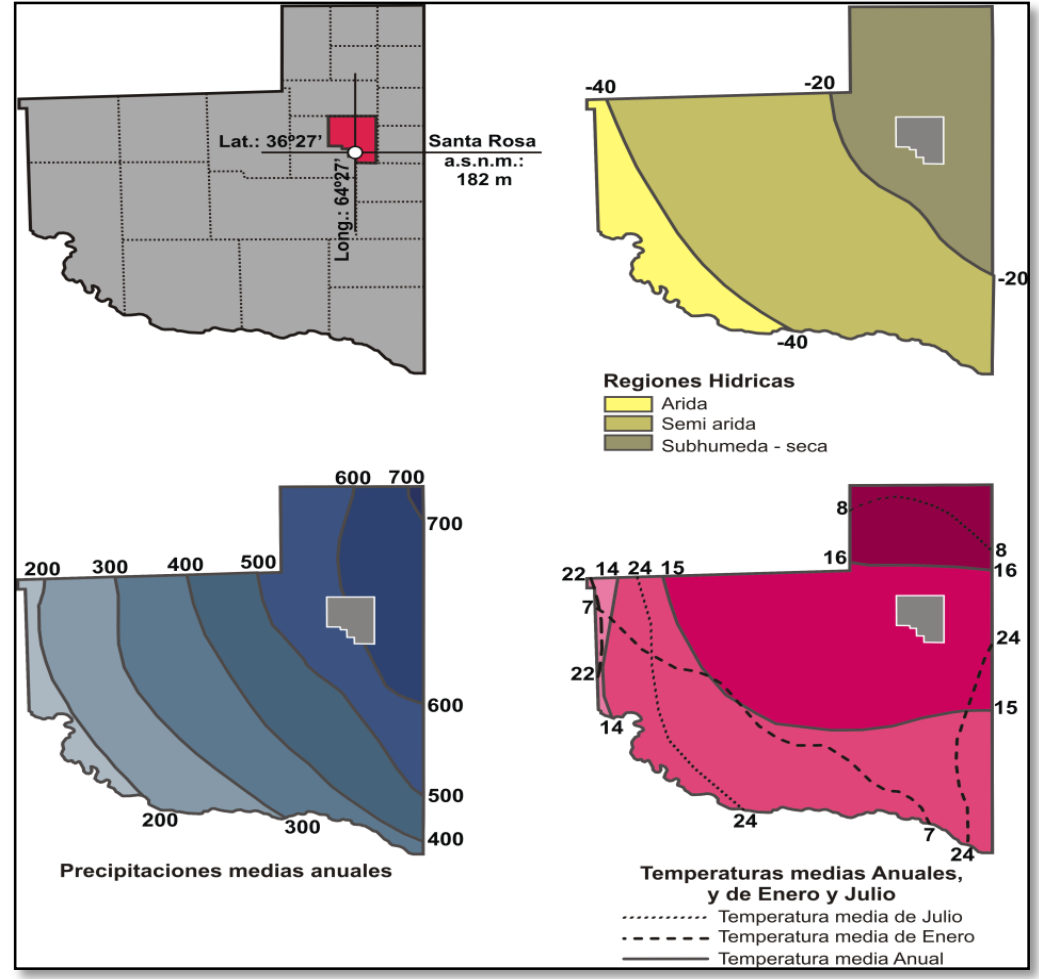

252 Filippín, C.; Sipowicz, E.; Larsen, S. F. 
Figura 3 - A la izquierda: Promedio de Precipitaciones Mensuales $(\mathrm{mm})$ y Promedio de Días con Precipitaciones - a la derecha: Radiación Global y Difusa en $\mathrm{kWh} / \mathrm{m}^{2}$ de Santa Rosa La Pampa
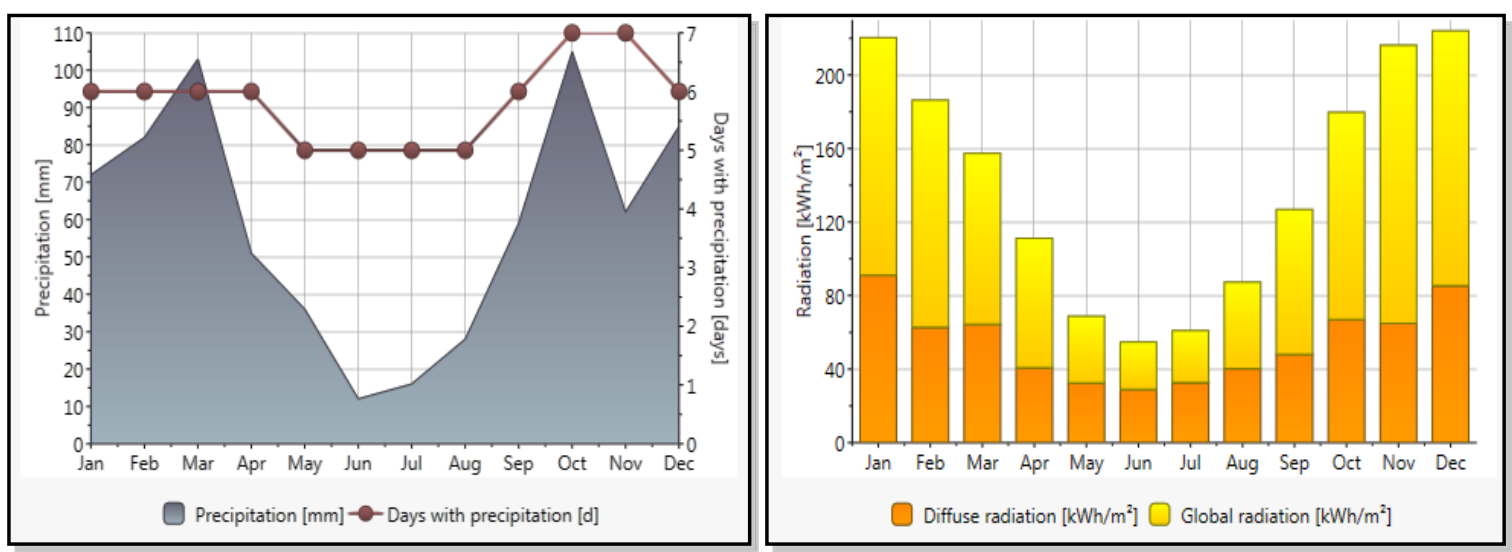

Figura 4 - Promedios diarios de Temperatura por mes de Santa Rosa, La Pampa - la zona de confort esta representada por el polígono verde; las líneas azules indican las temperaturas máximas, mínimas y medias promedio de cada mes; las curvas amarillas con línea llena indican la radiación solar directa, y las punteadas, la difusa. Ambas en $\mathrm{W} / \mathrm{m}^{2}$

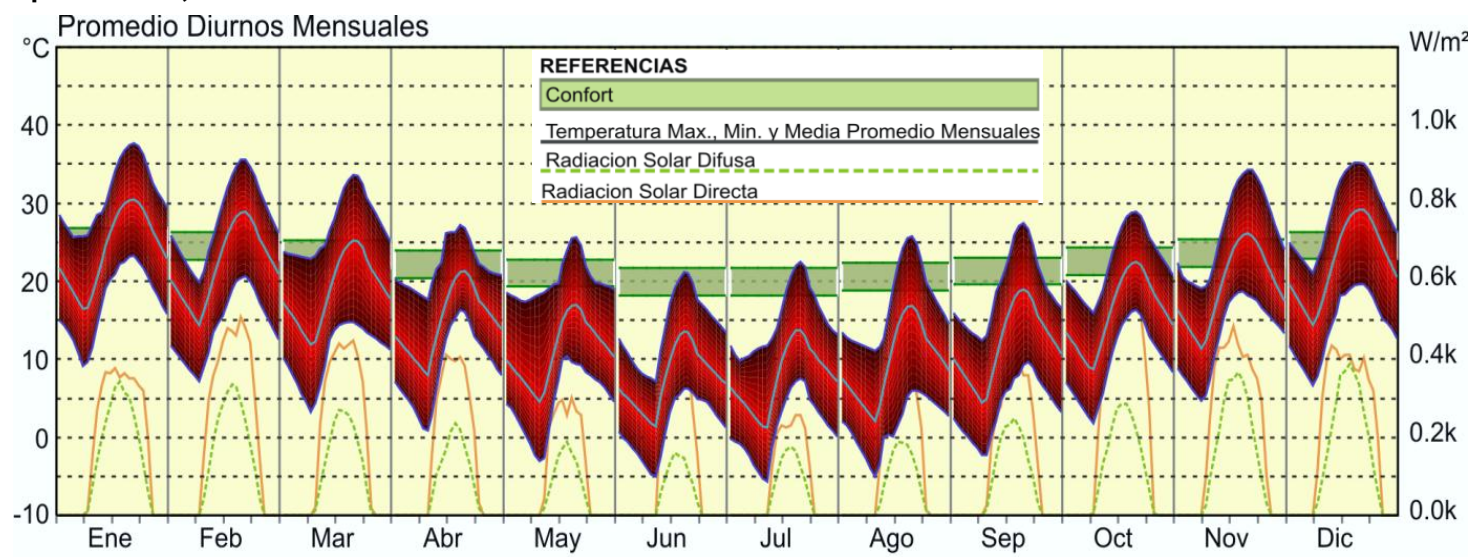

Santa Rosa tiene estaciones bien marcadas, con veranos cálidos e inviernos fríos y secos (Tabla 1). Los veranos, presentan temperaturas máximas medias de $30,3^{\circ} \mathrm{C}$ y mínimas medias de $13,8^{\circ} \mathrm{C}$. La diferencia térmica diaria es muy importante, considerándose una característica del clima local. Las lluvias alcanzan una media histórica anual de $610 \mathrm{~mm}$, concentrándose principalmente en los meses de primavera y verano, aumentando los últimos años en forma significativa (Figura 3). Los inviernos presentan temperaturas medias de $7,6^{\circ} \mathrm{C}$, mínimas medias de $1,5^{\circ} \mathrm{C}$ y máximas medias de $13,5^{\circ} \mathrm{C}$ (Figura 4). La amplitud térmica es de $12,0^{\circ} \mathrm{C}$ importante, como así también los días claros, donde el aprovechamiento solar es óptimo. En la Figura 5 se observa que las mejores orientaciones para aprovechamiento de la incidencia de radiación solar se encuentran entre los ángulos $+/-60^{\circ}$ respecto a la directriz Norte.
La Figura 6 muestra el diagrama psicométrico para los valores promedios mensuales de temperatura y humedad, los valores de temperatura media mínima y máxima, humedad relativa máxima y mínima. El diagrama se realizó a partir del software Weather Tool 2011- ${ }^{\odot}$ Autodesk, Inc.2010, en base a los Datos de la Estación Meteorológica Santa Rosa Aero (Datos de lecturas entre 1986 2005). La temperatura de confort que sirve de base para la determinación de las distintas zonas es TCON $=17.6+0.31 *$ TMAN. Siendo TCON, la temperatura de confort $\left({ }^{\circ} \mathrm{C}\right)$; y TMAN, la temperatura promedio anual de la localidad $\left({ }^{\circ} \mathrm{C}\right)$. Para la situación en estudio corresponde una temperatura de $22.4^{\circ} \mathrm{C}$ (AULICIEMS; SZOKOLAY, 2007). En el diagrama se observa una gran amplitud térmica estacional, con temperaturas en invierno por debajo de la banda de confort y humedades relativas moderadas. Hacia la izquierda del gráfico, para los valores de temperatura media mínima y humedad relativa 
media máxima de junio, julio y agosto se necesita calefacción auxiliar para ingresar a la zona de confort. El diseño arquitectónico de invierno amerita considerar las recomendaciones que surgen del diagrama. Si bien para valores medios y máximos medios de temperatura es suficiente disponer recurso solar (captación de radiación solar pasiva, inercia térmica), para valores mínimos medios de temperatura se debe recurrir a calefacción auxiliar mecánica.

El clima templado es complejo debido a la variabilidad estacional de las condiciones climáticas, lo cual hace necesario la incorporación de sistemas de control ambiental flexibles que puedan cambiar sus acciones según las circunstancias. (SERRA FLORENSA; $\mathrm{COCH}$ ROURA , 1995), afirman que mediante el diseño de espacios intermedios entre interior y exterior, se puede resolver el difícil problema del clima templado, que tiene normalmente menor dureza que otros tipos de climas pero con la característica esencial que pueden presentarse "todos a la vez".

Tabla 1 - Variables climáticas de Santa Rosa

\begin{tabular}{|c|c|c|c|c|}
\hline \multirow{5}{*}{$\begin{array}{l}\text { Valores } \\
\text { anuales }\end{array}$} & \multirow{3}{*}{ Temperatura } & \multirow{3}{*}{$\begin{array}{l}\text { media máxima } \\
\text { media mínima } \\
\text { media }\end{array}$} & \multirow{3}{*}{${ }^{\circ} \mathrm{C}$} & \multirow{2}{*}{$\begin{array}{c}23.4 \\
8.1 \\
\end{array}$} \\
\hline & & & & \\
\hline & & & & 15.5 \\
\hline & \multicolumn{2}{|l|}{ Humedad relativa } & $\%$ & 68 \\
\hline & \multicolumn{2}{|c|}{ Radiación solar media anual sobre superficie horizontal } & $\mathrm{MJ} / \mathrm{m}^{2}$ & 16.3 \\
\hline \multirow{7}{*}{ JULIO } & \multirow{4}{*}{ Temperatura } & mínima media & \multirow{4}{*}{${ }^{\circ} \mathrm{C}$} & 1.5 \\
\hline & & media & & 7.6 \\
\hline & & máxima media & & 13.5 \\
\hline & & mínima absoluta & & -5.9 \\
\hline & \multicolumn{2}{|l|}{ Amplitud térmica } & ${ }^{\circ} \mathrm{C}$ & 12.0 \\
\hline & \multicolumn{2}{|l|}{ Velocidad media del viento } & $\mathrm{Km} / \mathrm{h}$ & 10 \\
\hline & \multicolumn{2}{|c|}{ Radiación solar media sobre superficie horizontal* } & $\mathrm{MJ} / \mathrm{m}^{2}$ & 8.1 \\
\hline \multicolumn{4}{|c|}{ Grados-día de calefacción $\left(\mathrm{Tb}=18^{\circ} \mathrm{C}\right)$} & 1545 \\
\hline
\end{tabular}

Fuente: Servicio Meteorológico Nacional (2000).

Nota: *Grossi Gallegos y Righini (2007).

Figura 5 - Proyección Estereográfica de la Orientación Óptima basada en el promedio diario de incidencia de radiación solar sobre superficies verticales; en rojo las peores orientaciones y en amarillo, las mejores; la línea Verde indica el promedio anual, la azul el periodo con bajas temperaturas, y la roja el periodo sobrecalentado

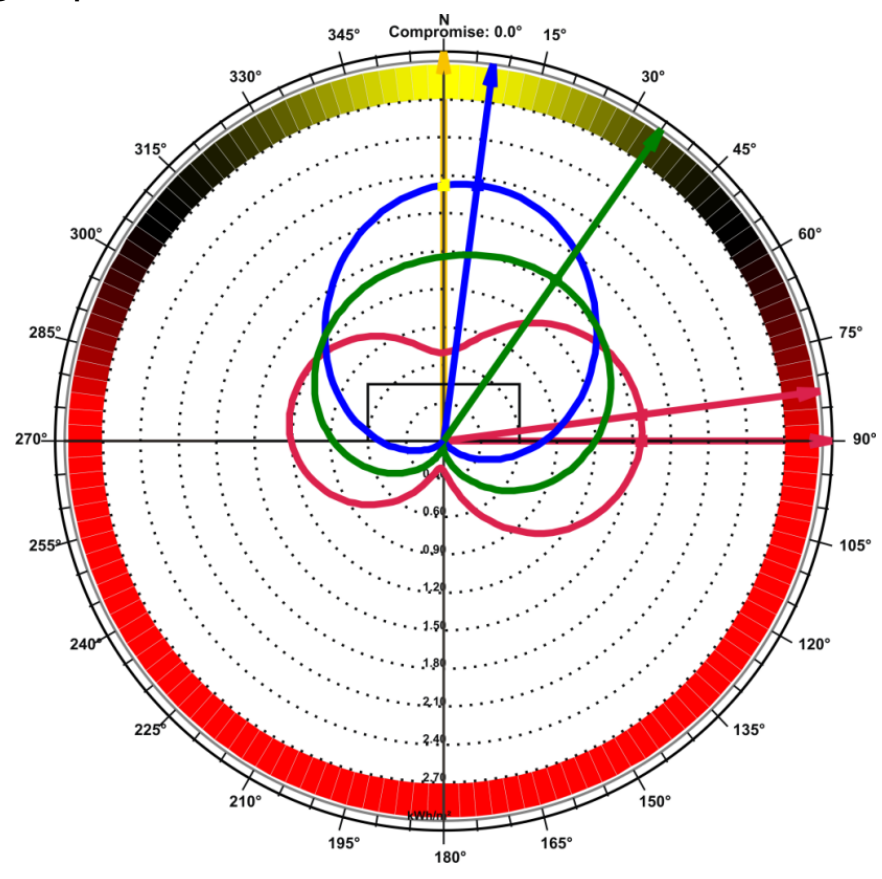

254 Filippín, C.; Sipowicz, E.; Larsen, S. F. 
Figura 6 - Diagrama Psicométrico que refleja el confort, las condiciones climáticas de Santa rosa, y las estrategias de acondicionamiento pasivo que colaboran para lograr confort habitacional

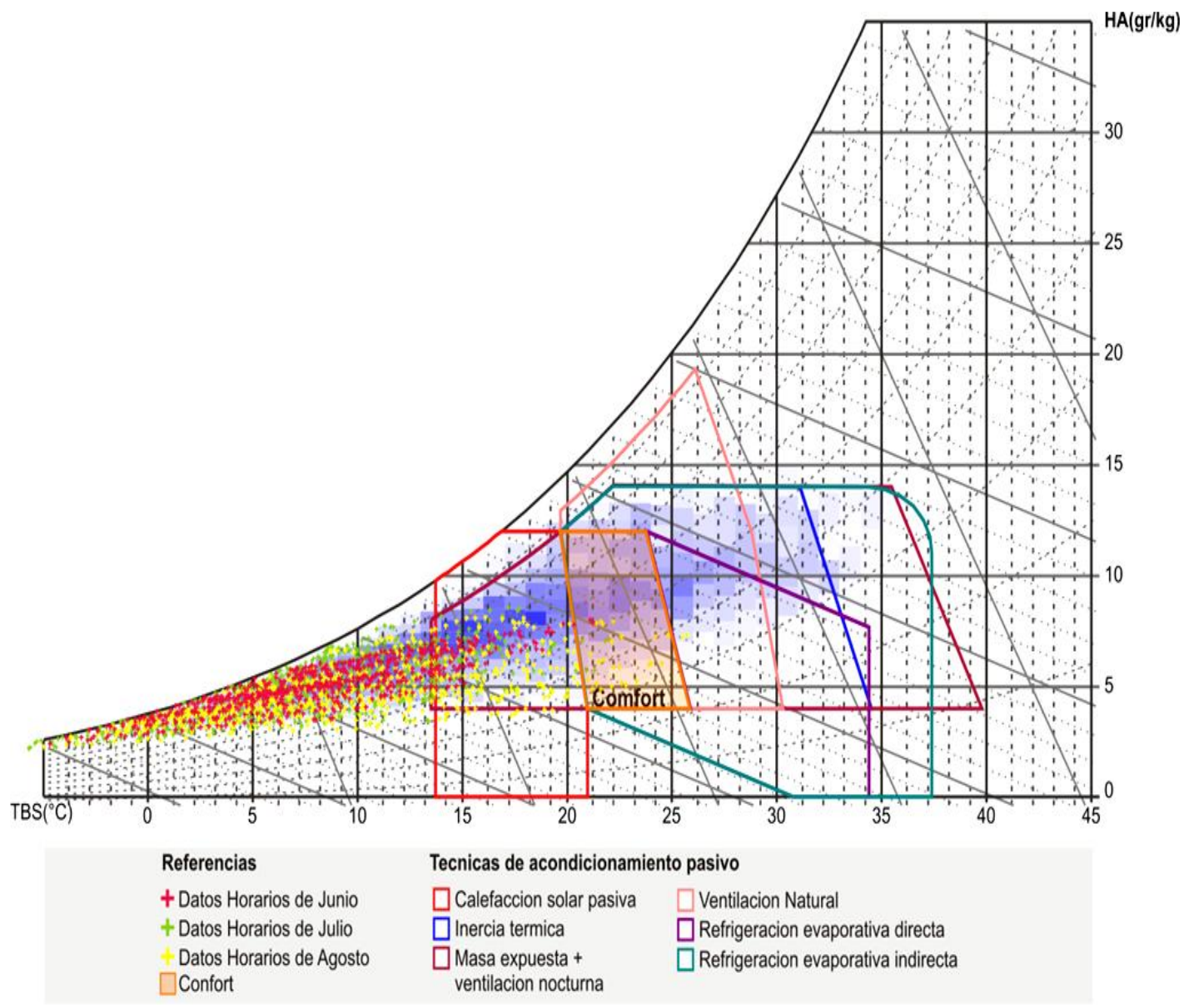

\section{Descripción tipológica y tecnológica de las viviendas en estudio: Viviendas "Cajón" de la región Pampeana}

\section{Antecedentes}

El mejoramiento de los edificios existentes representa una oportunidad significativa para reducir el consumo global de energía y las emisiones de gases de efecto invernadero. Lograr la sostenibilidad en el entorno construido a un costo relativamente bajo readaptando tecnologías fácilmente disponibles es un importante reto técnico. Los métodos para identificar la solución más rentable son variados. En este trabajo se busca identificar la idea rectora que da lugar a la expresión espacial de la tipología de vivienda característica de la región pampeana. El método que se aplica se desarrolla en base al análisis de los elementos y las relaciones que constituyen la forma arquitectónica, considerando la tecnología aplicada en cada caso.
Nuestro objeto de estudio en este trabajo es la tipología ${ }^{2}$ de vivienda cajón. La "Casa Cajón”, es un tipo de vivienda individual popular suburbana, cuya difusión tuvo lugar a lo largo de todo el territorio argentino en la segunda mitad del siglo XX. El tipo de "casa cajón" constituida a partir de la sala central, caracteriza a la vivienda popular moderna de fisonomía modernista y de lenguaje morfológicamente neutro despojado de todo atributo formal.

A mediados de la década del treinta, distintos factores generaron la transformación del modelo

\footnotetext{
${ }^{2}$ Tipo-logía, disciplina que estudia los tipos. Es una concepción académica cuya finalidad es generar un instrumento de análisis y de clasificación de los tipos. La tipología se ocupa sobre todo de la búsqueda de similitudes o vínculos estructurales entre las cosas tratando de establecer raíces etimológicas comunes que enmarcan diferentes fenómenos. Hablar de tipologías es hablar de procesos de análisis e interpretación, en donde la técnica de la propia interpretación se convierte en herramienta básica para la descripción de la arquitectura, y el análisis, marca las pautas, descompone el objeto para confirmar o desconformar la interpretación. Tipo, es un concepto o idea abstracta que describe una estructura formal y que es obtenido de un grupo de objetos, de los que se han abstraído cualidades genéricas comunes. Los tipos explicitan un orden entre elementos arquitectónicos y relaciones morfológicas. (VERA BOTI, 2013).
} 
residencial académico existente en un instrumento mucho más pequeño y sencillo: el impulso de la revolución tecnológica (incorporación y aceptación masiva del uso de técnicas del acero y el hormigón); el paulatino surgimiento de una industria de la construcción cada vez más diversificada como resultado de la crisis y sustitución de importaciones de los cuarenta; la modificación de los estándares y modo de vida de la sociedad (reducción del núcleo familiar); y la necesidad del momento histórico de adecuarse a los condicionamientos mercantiles del suelo urbano (mayor aprovechamiento del terreno y posibilidad de crecimiento en altura sin límites). Así, el modelo de la "casa chorizo", sobreviviente de la transformación y adaptación al medio de la casa pompeyana, comenzará a ser reemplazado hacia los cuarenta por la casa tipo "cajón", como solución artesanal y sintética a las necesidades de la base de la pirámide social (BRITO; MAUR, 2013).

Como atando aquel 'chorizo' por los puntas, se la cerró sobre sí misma, inaugurando el reino de los dos dormitorios con baño al medio, contra uno de sus lados, perpendiculares al frente, y comunicados por un 'paso' al comedor y cocina, con lo que se pudo circular por toda ella sin salir al patio o tener que andar de habitación en habitación. Y fue el nuevo clásico de la construcción, a tal punto que se la adoptó para desarrollar planes de vivienda del Banco Hipotecario Nacional, que alcanzaron a todo el país. (GONZÁLEZ PODESTÁ, 2013).

En esta transformación, la galería de la puerta de calle pasó a ser el "porch"; el vestíbulo de la casa chorizo fue reducido y rebautizado como "hall", el comedor pasó a ser el "living", a los dormitorios se les introdujo el "placard", y la cocina, continuó siendo el lugar de reunión y vida de la casa, adosada y separada a la vez por una arcada con el comedor de diario. Por otro lado, hubo cosas que no fueron modificadas: el jardin al frente, el metro veinte de pasillo sobre la otra medianera (acceso a la cocina y a departamentos al fondo) y el fondo continuó albergando al gallinero, el níspero o la higuera. El modelo que se hizo más frecuente constaba de 2 dormitorios y de una superficie de $60 \mathrm{~m}^{2}$, con un perímetro de $35 \mathrm{~m}$. Sus características tipológicas son:

(a) introversión: el funcionamiento de este tipo de vivienda se resuelve exclusivamente en su interior, sin tener que requerir circulaciones externas (que caracterizan a todas las tipologías previamente empleadas); (b) compacidad: cada ambiente tiene las dimensiones estrictamente necesarias;

(c) diferenciación funcional y ordenamiento de funciones bien definidas: las habitaciones se diferencias en su orientación, localización y dimensiones, de acuerdo con las funciones principales para las que están diseñadas;

(d) la ausencia del gesto audaz, la simplicidad armónica de los volúmenes;

(e) costo mínimo: la introversión y la compacidad permiten una disminución de costos;

(f) sistematización y modulación de los espacios y fachadas en un intento de estandarización;

(g) la valorización del entorno y apertura al exterior, en oposición a las tipologías organizadas, en base a patios internos. Ideales higienistas de asoleamiento y ventilación; $y$

(h) la aplicación de nuevas tecnologías constructivas y de servicios (electrificación de las cocinas, la ventilación mecánica, la iluminación, etc.).

\section{Viviendas de estudio}

La ciudad de Santa Rosa, ubicada en el cruce de las rutas nacionales $\mathrm{N}^{\mathrm{o}} 5$ y $\mathrm{N}^{\mathrm{o}} 35$, equidistante a los grandes centros urbanos del país como Buenos Aires al Este, Córdoba y Rosario al Norte, Mendoza al Oeste y Neuquén y el valle rionegrino al Sur, fue fundada en el año 1892. El proceso de crecimiento de la población de Santa Rosa, tuvo dos hitos fundamentales: la llegada de los inmigrantes en las primeras décadas del siglo $\mathrm{XX}$ y la provincialización ${ }^{3}$ en 1951. Alrededor de 1935, a Santa rosa se le incorporan servicios de luz eléctrica, agua corriente y red cloacal, lo que fomento el crecimiento horizontal de la ciudad hacia el Norte generando un eje entre dos polos de atracción: el hospital Regional y la Escuela Hogar. En esta expansión, se ocupó, entre otros, el barrio Villa del Busto. Mientras que Villa Alonso se compacta hasta la Av. Belgrano. Así, la estructura interna de Santa Rosa experimenta una expansión importante y comienzan a tener identidad propia Zona Norte, Villa Alonso, Barrio Fitte y Villa Santillán. (COVAS; TOURN; PEREZ, 1986). Quedando conformada la estructura urbana en forma de retícula y caracterizada en su mayoría por edificación urbana de tipología moderna, compacta con crecimiento en horizontal.

Las viviendas en estudio (Figura 7) están emplazadas en barrios de baja densidad de

\footnotetext{
${ }^{3}$ Cuando Santa Rosa se convierte en la capital de la provincia de La Pampa y es desde entonces la sede del poder político.
} 
edificación en los cuales predomina la tipología compacta, entre medianeras y de un solo piso. $\mathrm{C} 1$ y C2 están localizadas en el barrio "Villa Alonso", hacia el este de la ciudad y C3 y C4 en el barrio "Villa del Busto', hacia el norte de Santa Rosa Las viviendas son másicas, de una sola planta y sin aislamiento térmico en su envolvente. Las paredes exteriores son de ladrillo común de $0.30 \mathrm{~m}$ de espesor con una transmitancia térmica $(\mathrm{K})$ de 1.88 $\mathrm{W} / \mathrm{m}^{2} \mathrm{~K}$. La norma IRAM 11605 (INSTITUTO..., 1996) recomienda valores máximos de $\mathrm{K}$ para muros y techos, y para las distintas regiones bioambientales del país, valores que corresponden a tres niveles de confort higrotérmico (A, B y C). En las viviendas en estudio el valor de $\mathrm{K}$ del muro no alcanza el nivel menos exigente (Nivel $\mathrm{C}, \mathrm{K}=$ $\left.1.59 \mathrm{~W} / \mathrm{m}^{2} \mathrm{~K}\right)$. La estructura resistente de la cubierta de las viviendas $\mathrm{C} 3$ y $\mathrm{C} 4$ es un forjado con perfilería de hierro y ladrillo macizo y, en $\mathrm{C} 1$ y $\mathrm{C} 2$, es un forjado de viguetas pretensadas, bloques cerámicos y capa de compresión de hormigón. Sobre la estructura tienen un contrapiso de pendiente con un espesor promedio de $10 \mathrm{~cm}$ terminado con membrana hidrófuga, excepto en C2 cuya cubierta es de teja francesa con mortero de asiento. La transmitancia térmica es de alrededor de $1.00 \mathrm{~W} / \mathrm{m}^{2} \mathrm{~K}$, valor superior al recomendado por la misma Norma (K entre 0.29 y 076, niveles A y C, respectivamente). Las ventanas en las cuatro viviendas tienen cortina de enrollar y vidrio simple. En C1, C3 y C4 las ventanas son de madera maciza, en $\mathrm{C} 2$ son de aluminio pre pintado. El factor de exposición es mayor en $\mathrm{C} 2$ $(73 \%)$ por tener su pared orientada al Oeste expuesta al exterior. El índice de compacidad varía entre el 57 y el $73 \%$. Las viviendas se evaluaron durante julio y agosto de 2010. La disponibilidad de instrumental impidió la simultaneidad del monitoreo. Se utilizaron dataloggers HOBO U8 y U12 (001 y 011) de temperatura y humedad relativa que se ubicaron en cada una de las áreas funcionales de cada vivienda y en el espacio exterior. La radiación solar se midió con una estación meteorológica inalámbrica HOBO.

\section{Análisis de resultados}

\section{Monitoreo experimental}

En la (Figura 8) se observan los resultados del monitoreo de la vivienda $\mathrm{C}_{1}$ entre el 13 y el 20 de julio de 2010. Fue un período frío con temperaturas externas que llegaron hasta los $-5^{\circ} \mathrm{C}$. La temperatura en las áreas de uso diurno y nocturno nunca estuvo por debajo de $\operatorname{los} 15^{\circ} \mathrm{C}$ y por encima de los $24^{\circ} \mathrm{C}$. El uso de la ducha en el baño que se ubica dentro del quincho provocó el ascenso de la temperatura en varios días del período. La temperatura interior promedio $\left(19.9^{\circ} \mathrm{C}\right)$ estuvo $16.3^{\circ} \mathrm{C}$ por encima de la exterior $\left(3.6^{\circ} \mathrm{C}\right)$. El consumo diario promedio de gas natural fue de alrededor de $0.11 \mathrm{~m}^{3} / \mathrm{m}^{2}$ (Figura 8).

En la (Figura 9) se observa el comportamiento de la vivienda $\mathrm{C} 2$ que alcanzó una temperatura promedio de $21.8^{\circ} \mathrm{C}, 14.1^{\circ} \mathrm{C}$ por encima de la media exterior $\left(7.7^{\circ} \mathrm{C}\right)$. En la temperatura promedio interior no se contempla el área funcional quincho, sector en el cuál el calefactor se encendió esporádicamente. El consumo promedio diario de gas natural medido fue de $0.22 \mathrm{~m}^{3} / \mathrm{m}^{2}$. Bajo condiciones climáticas menos adversas, $\mathrm{C}_{2}$ que es una vivienda con mayor exposición y además, muy expuesta hacia los vientos fríos dominantes, consumió un $100 \%$ más de energía que $\mathrm{C}_{1}$ para alcanzar $2^{\circ} \mathrm{C}$ más (Tabla 2 ).

El comportamiento térmico de la vivienda $\mathrm{C}_{3}$ se observa en la (Figura 10). El área funcional más usada, el comedor, es el espacio que alcanzó las temperaturas más altas $\left(20.0^{\circ} \mathrm{C}\right)$. El calefactor del estar no se encendió, situación que se refleja en la curva correspondiente. Los dos dormitorios mantienen su comportamiento térmico entre las dos áreas funcionales anteriores. La temperatura promedio de $\mathrm{C}_{3}$ fue de $16.0^{\circ} \mathrm{C}, 12.4^{\circ} \mathrm{C}$ por encima de la media exterior $\left(3.6^{\circ} \mathrm{C}\right)$. El consumo de gas natural promedio fue de $0.10 \mathrm{~m}^{3} / \mathrm{m}^{2}$, el menor de los cuatro casos estudiados (Tabla 2). Un trabajo anterior (FILIPPÍN; FLORES LARSEN, 2012) también mostró que el consumo de electricidad promedio diario en esta vivienda era inferior incluso al promedio de la ciudad. El uso racional de la energía está asociado no a la nivel de ingresos de los usuario, sino a la idiosincrasia de ellos, quienes manifestaron vivir confortablemente bajo las condiciones medidas. Si se compara con $\mathrm{C}_{1}$ (igual período de medición) se observa que para casi $4{ }^{\circ} \mathrm{C}$ de diferencia de la temperatura promedio interior, la reducción del consumo es de un $10 \%$.

Por último $\mathrm{C}_{4}$, es una vivienda que tiene su fachada principal orientada al sur y con sus dormitorios al norte. Está ocupada por dos personas jubiladas. En el área funcional cocinacomedor (con orientación sur), la temperatura máxima llega a los $23.0^{\circ} \mathrm{C}$, situación esperable por el uso específico del espacio. El estar, también hacia el sur, más frío, necesitó suplementar la calefacción con una estufa halógena durante $2 \mathrm{~h}$ diarias. (Figura 11) La temperatura promedio interior fue de $17.9^{\circ} \mathrm{C}, 10.5^{\circ} \mathrm{C}$ por encima de la exterior $\left(7.4^{\circ} \mathrm{C}\right)$. El consumo promedio diario de gas natural estuvo alrededor de los $0.14 \mathrm{~m}^{3} / \mathrm{m}^{2}$ (Figura 11). 
Figura 7 - Casos de estudio: Viviendas de tipología compacta emplazadas en barrios de baja densidad edilicia de la ciudad de Santa Rosa, La Pampa

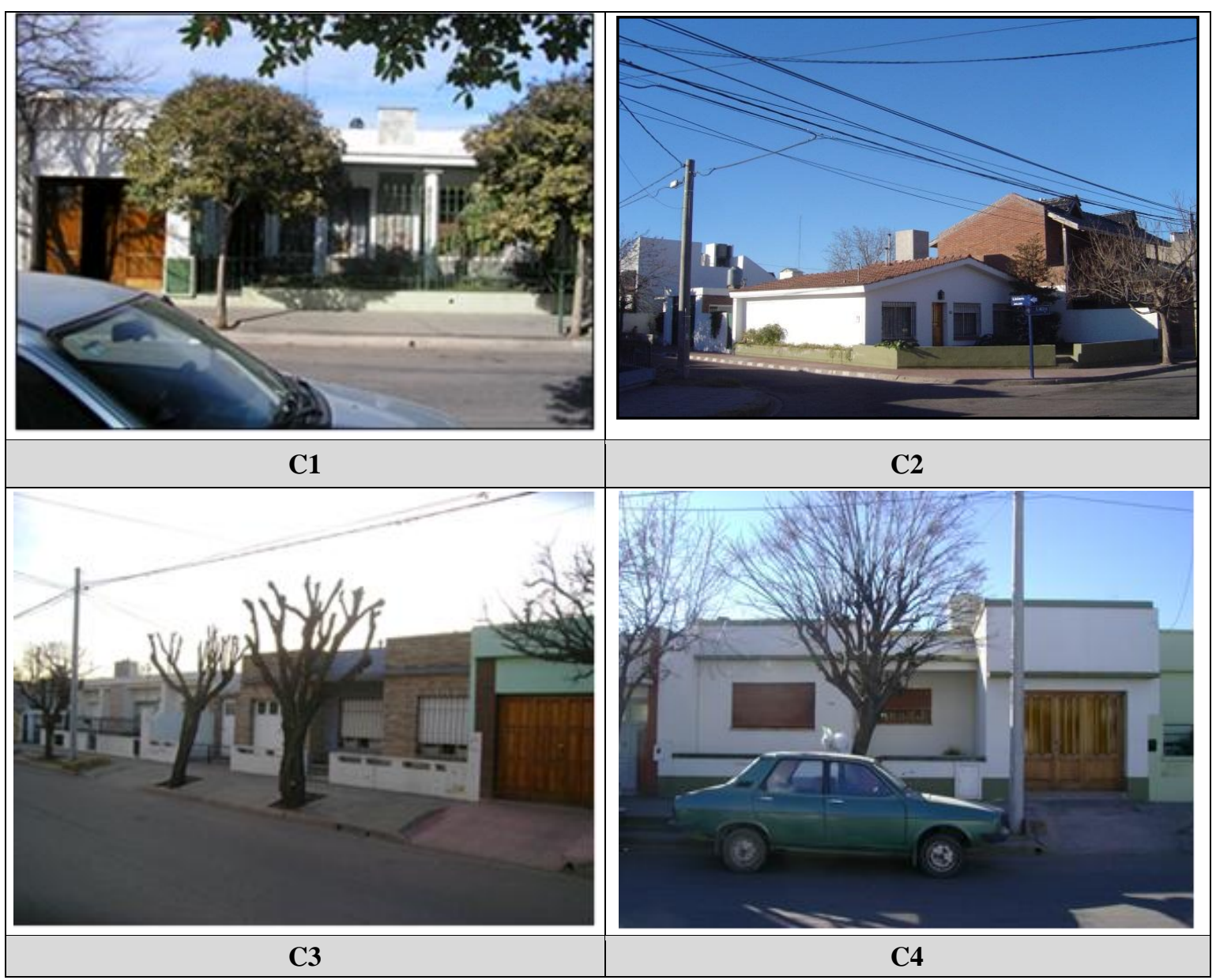

Figura 8 - Evolución de la temperatura en C1 entre el 13 y el 20 de Julio de 2010

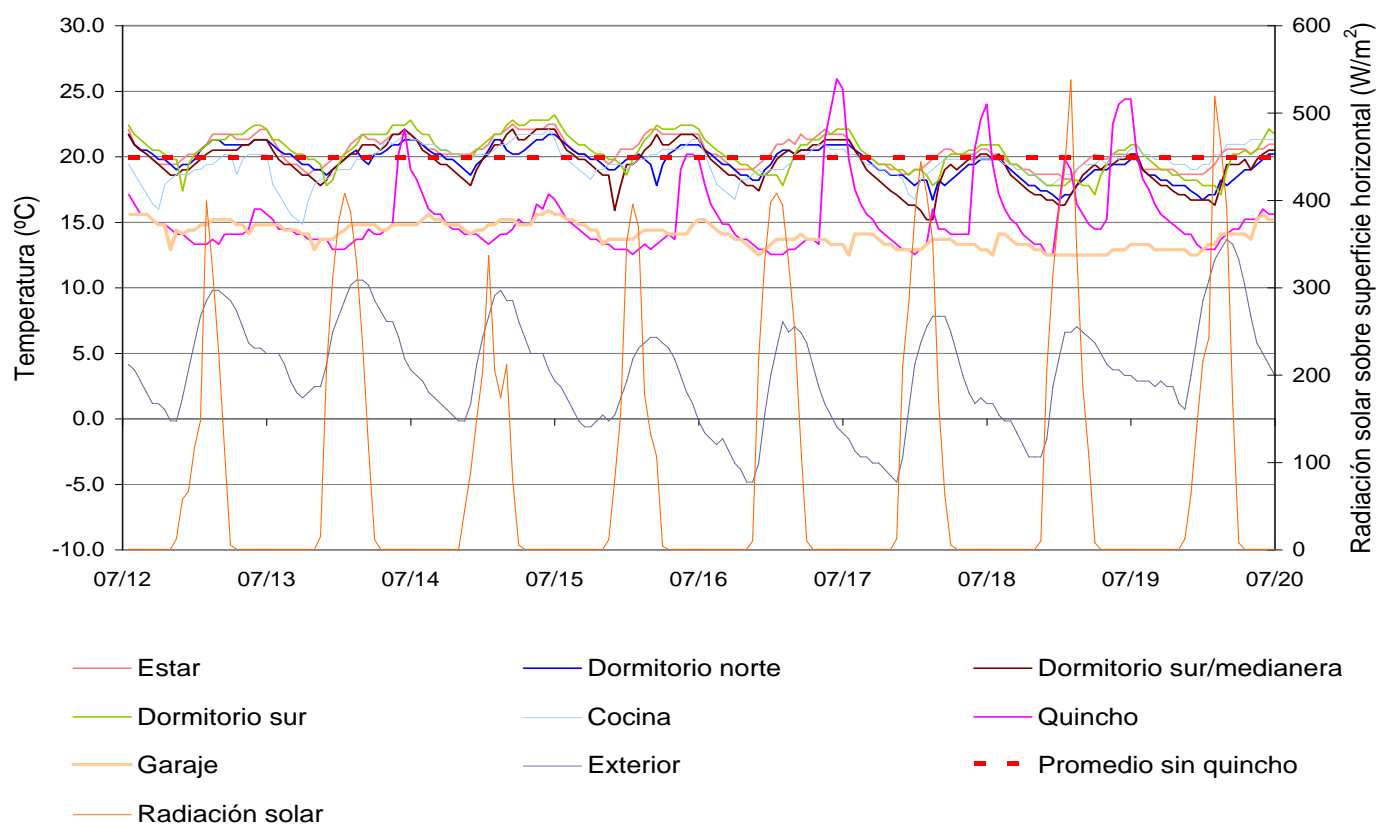

258 Filippín, C.; Sipowicz, E.; Larsen, S. F. 
Figura 9 - Evolución de la temperatura en C2 entre el 11 y el 16 de Agosto de 2010

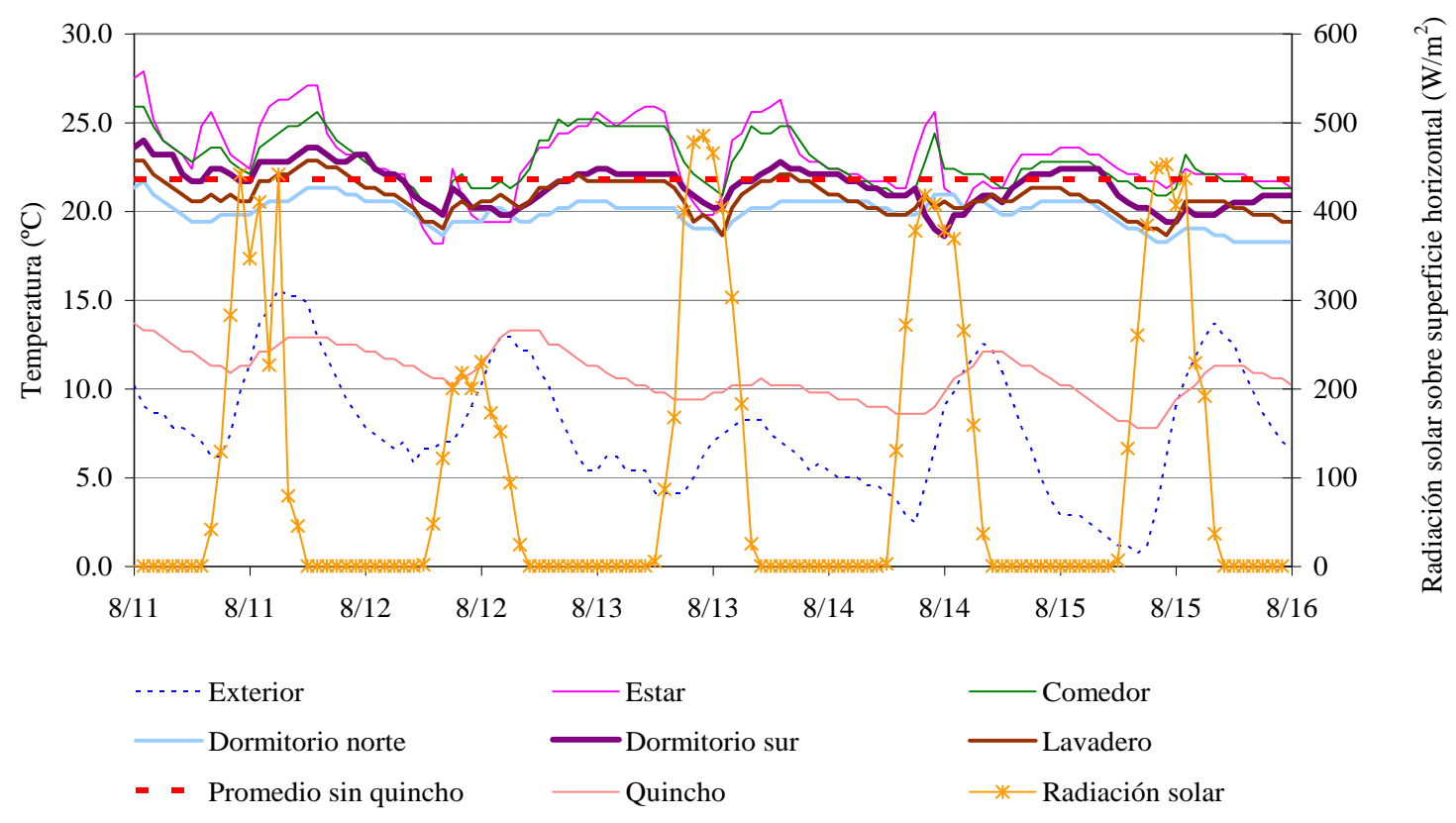

Tabla 2 - Comportamiento térmico-energético de las viviendas en el invierno de 2010

\begin{tabular}{|c|c|c|c|c|}
\hline \multirow[b]{2}{*}{ Vivienda } & \multicolumn{2}{|c|}{ Temperatura promedio $\left({ }^{\circ} \mathrm{C}\right)$} & \multirow{2}{*}{$\begin{array}{c}\text { Consumo de gas natural } \\
\text { promedio diario/m } \\
\left(\mathrm{m}^{3} / \mathrm{m}^{2}\right) \\
\end{array}$} & \multirow[b]{2}{*}{ Período de medición } \\
\hline & exterior & interior & & \\
\hline $\mathrm{C}_{1}$ & 3.6 & 19.9 & 0.11 & 13 al 19 de julio \\
\hline $\mathrm{C}_{2}$ & 7.7 & 21.8 & 0.22 & 11 al 15 de agosto \\
\hline $\mathrm{C}_{3}$ & 3.6 & 16.0 & 0.10 & 13 al 19 de julio \\
\hline $\mathrm{C}_{4}$ & 7.4 & 17.9 & 0.14 & 31 de julio al 6 de agosto \\
\hline
\end{tabular}

Figura 10 - Evolución de la temperatura en C 3 entre el 13 y el 20 de Julio de 2010

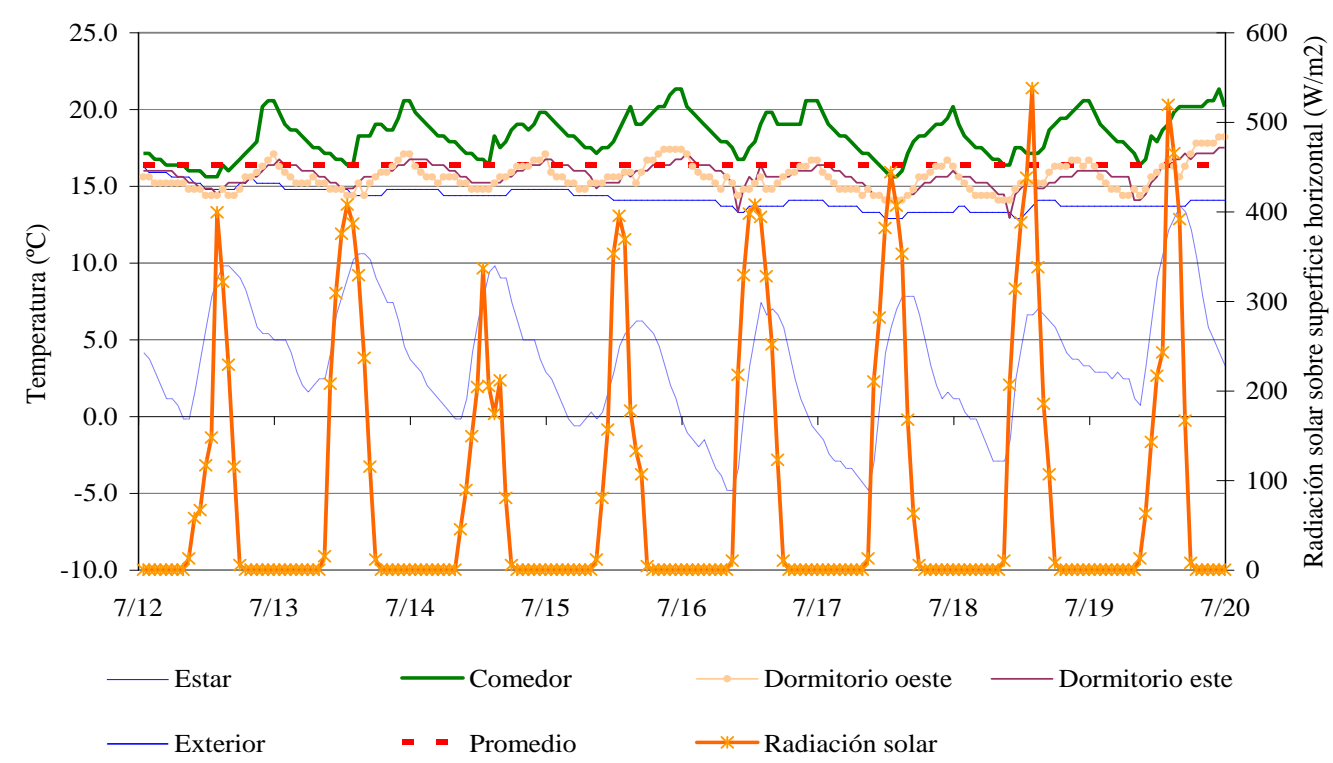


Figura 11 - Evolución de la temperatura en C4 entre el 31 de Julio y el 6 de Agosto de 2010

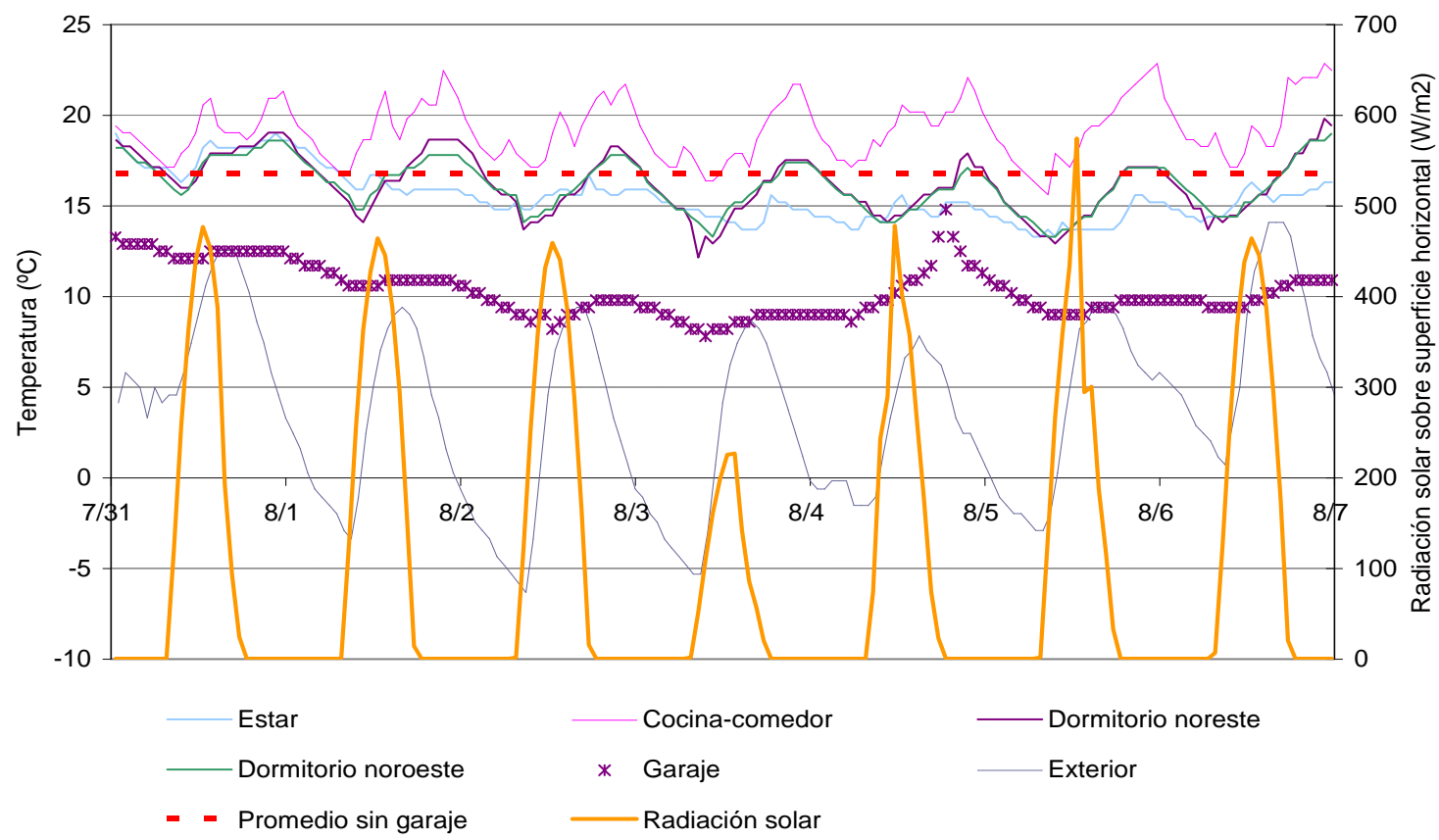

En la Tabla 2 se observa la temperatura promedio, interior y exterior, en el período de medición y el consumo diario de gas natural medido. Según el (INSTITUTO..., 2010) por cada grado que aumentemos la temperatura interior, se incrementa el consumo de energía aproximadamente en un $7 \%$. En nuestro caso si se toman las viviendas $\mathrm{C}_{1} \mathrm{y}$ $\mathrm{C}_{3}$ monitoreadas en el mismo período, una temperatura promedio interior de casi $3^{\circ} \mathrm{C}$ menos en $\mathrm{C}_{3}$ acusa un consumo menor de un $10 \%$ de gas natural en calefacción. La vivienda $\mathrm{C}_{2}$, bajo condiciones climáticas externas más benignas muestra el valor más alto de temperatura promedio interior. El consumo de energía en calefacción es un $55 \%$ superior $\mathrm{a}_{3}$

\section{Comportamiento energético}

La Tabla 3 muestra los resultados del análisis del consumo histórico de gas natural para el período 2000-2010. $\mathrm{C}_{1}$ es la vivienda que presenta el menor coeficiente de variación entre años para los valores anuales y bimestrales. El valor es algo superior para el período julio y agosto, situación totalmente compatible con la rigurosidad climática de esos meses. $\mathrm{C}_{2}, \mathrm{C}_{3}, \mathrm{y}_{4}$ tiene un coeficiente de variación superior al de $C_{1}$. Tanto $C_{2}$ como $C_{4}$ muestran la mayor variación en el consumo de gas natural durante julio y agosto dentro del período histórico considerado. Es posible que el consumo haya estado condicionado por algunas particularidades, entre ellas: la orientación hacia el sur de $\mathrm{C}_{2}$ y $\mathrm{C}_{4}$, la mayor exposición de $\mathrm{C}_{2}$, la situación laboral de la propietaria de $\mathrm{C}_{2}$, quien dentro del período histórico del análisis del consumo de gas se jubila, en consecuencia permanece más horas en el hogar con otros requerimientos térmicos, al igual que en $\mathrm{C}_{4}$ habitada por dos mujeres adultas mayores jubiladas y más sedentarias. Aún con estos mayores coeficientes de variación es posible inferir que al ambiente térmico en los años anteriores ha sido similar al del período de monitoreo. En los cuatros casos el consumo de energía acuerda con el diagrama de la (Figura 6), en donde aún con disponibilidad de sol, se requiere de calor auxiliar para ingresar a la zona de confort. Los meses de julio y agosto necesitan diariamente, y durante 24 horas, consumo de energía para alcanzar las condiciones de confort. El consumo anual promedio de gas natural en calefacción por área de superficie útil es de 91.5, 328.8, 109.9 y 186.7 $\mathrm{kWh} / \mathrm{m}^{2}$ para $\mathrm{C}_{1}, \mathrm{C}_{2}, \mathrm{C}_{3}$ y $\mathrm{C}_{4}$, respectivamente. Nuevamente $\mathrm{C}_{2}$ que tuvo un consumo diario medido del fluido superior a las otras viviendas muestra el mayor consumo anual en calefacción por metro cuadrado de superficie útil. Si bien la vivienda mostró la temperatura interior promedio más alta en el período de monitoreo de 2010 $\left(21.8^{\circ} \mathrm{C}\right)$, el mayor consumo de fluido podría estar asociado a la mayor superficie expuesta de la envolvente con el exterior. 
Tabla 3 - Consumo de gas natural entre 2000 y $2010\left(\mathrm{~m}^{3}\right)$ - CV (coeficiente de variación)

\begin{tabular}{c|c|c|c|c|c|c|c|c|c}
\hline \multirow{2}{*}{} & \multicolumn{3}{|c|}{ Anual } & \multicolumn{3}{c|}{ Bimestral } & \multicolumn{3}{c}{ Julio - Agosto } \\
\cline { 2 - 10 } & promedio & $\begin{array}{c}\text { desvío } \\
\text { standard }\end{array}$ & CV & promedio & $\begin{array}{c}\text { desvío } \\
\text { standard }\end{array}$ & $\mathbf{C V}$ & promedio & $\begin{array}{c}\text { desvío } \\
\text { standard }\end{array}$ & CV \\
\hline C1 & 2370.4 & 154.1 & 6.5 & 395.1 & 25.7 & 6.5 & 907.0 & 81.6 & 9.0 \\
C2 & 2600.7 & 271.1 & 13.5 & 334.5 & 45.2 & 13.5 & 793.6 & 170.2 & 21.5 \\
C3 & 1178.0 & 163.6 & 13.9 & 196.3 & 27.3 & 13.9 & 451.4 & 55.0 & 12.2 \\
C4 & 1417.7 & 185.2 & 13.1 & 236.3 & 30.9 & 13.1 & 527.1 & 90.7 & 17.2 \\
\hline
\end{tabular}

\section{Estimación del comportamiento térmico-energético de un mosaico urbano a partir de viviendas monitoreadas}

En Argentina, la producción y retroffiting de edificios ha crecido significativamente en los últimos años, correspondiendo el mayor porcentaje a los residenciales. En este sentido es indispensable desarrollar herramientas analíticas que permitan comprender y monitorear los procesos involucrados en el fenómeno de la urbanización y cuantificar sus consecuencias energético-ambientales a partir de una unidad representativa (mosaico urbano), la aptitud de los distintos sectores de la ciudad para el aprovechamiento energético de la radiación solar en las diferentes texturas urbanas y sus áreas de disipación térmica, determinando el potencial energético de las mismas (VIEGAS, 2010). En este contexto y a partir de los resultados obtenidos nos preguntarnos, cuál es el comportamiento en general de viviendas tipológica y tecnológicamente similares en los mismos sectores urbanos de las unidades analizadas? Cuál sería la potencialidad de una posible intervención tecnológica para mejorar las condiciones de confort y para disminuir el consumo energético? Para responder a estos interrogantes, planteamos como experiencia piloto una extrapolación de los resultados en un mosaico urbano de Villa del Busto en el cuál hay dos viviendas medidas (C3 y C4) (Figura 12). A través de la observación directa de cada una de las cuadras se detectaron viviendas con la misma tipología de C3 y C4. Se incorporan al análisis sólo aquellas viviendas que tienen consumos históricos de gas natural sin interrupción desde 2000 y con bajo coeficiente de variación entre años para garantizar, en cierta forma, la permanencia de la misma familia con un modelo tradicional de ocupación de la vivienda. La superficie de cada vivienda se obtuvo en la Dirección General de Catastro de la Provincia.
La Tabla 5 muestra el consumo promedio anual y para julio de gas natural en calefacción entre 2000 y 2009 en $\mathrm{kWh}$ de acuerdo a los datos en $\mathrm{m}^{3}$ de Tabla 4. Se incorpora a la misma Tabla el consumo de gas durante el año 2010 (año del monitoreo experimental de las viviendas de referencias). Los valores se detallan en $\mathrm{kWh} / \mathrm{m}^{2}$ y $\mathrm{kWh} / \mathrm{m}^{2} /$ día. El consumo promedio anual de energía para calefacción de las viviendas entre el año 2000 y 2009 es de $102.2 \mathrm{kWh} / \mathrm{m}^{2}$ con un coeficiente de variación entre ellas del 30.2.3\%. La variación estaría asociada entre otras variables, a las costumbres de los usuarios, a la disponibilidad del recurso solar, a la cantidad de vanos y sus dimensiones. El valor es un $15 \%$ inferior al consumo promedio de las viviendas monitoreadas. El consumo promedio anual de energía en calefacción de las viviendas seleccionadas en la unidad representativa es de un $31 \%$ superior al valor definido por SARTORI, HESTNES, 2007 para los edificios de bajo consumo $\left(70 \mathrm{kWh} / \mathrm{m}^{2}\right)$. El promedio del consumo diario de energía por metro cuadrado de superficie calefaccionada para viviendas de igual tipología dentro del mosaico urbano es de $0.95 \mathrm{kWh} / \mathrm{m}^{2} /$ día, valor muy cercano al registro medido de las viviendas monitoreadas que mostraron una temperatura promedio entre los 16.0 y $18.0^{\circ} \mathrm{C}$.

La Tabla 4 muestra una síntesis de los resultados de las viviendas de referencia: C3 y C4. Hasta 2009 el consumo de gas natural en calefacción durante julio fue de 37.2 y $40.0 \mathrm{kWh} / \mathrm{m} 2$ para C3 y $\mathrm{C} 4$, respectivamente. Durante 2010 el valor disminuyo en C3 y se incrementó en C4. En la Tabla se observa el consumo de gas natural promedio y el coeficiente de variación (período 2000-2009) de las viviendas que se estudian en la extrapolación. Dos de ellas tienen coeficientes más altos pero no se descartan de la muestra, ameritan en realidad una evaluación particularizada. En la muestra prevalecen las viviendas orientadas al oeste. Todas tienen climatización mecánica y la mayoría tienen un coeficiente de variación en el consumo de gas natural histórico en el período frío más alto que en el análisis anual, situación 
previsible para un clima templado frío ya que el coeficiente de variación de la temperatura mínima de julio para el período 2000-2010 fue del 117.4\% mientras que la dispersión de la temperatura mínima promedio anual fue del $8 \%$. Tabla 6 muestra el consumo de gas natural en calefacción promedio anual y para julio entre 2000 y 2009. Los resultados anuales $/ \mathrm{m}^{2}$ superan el valor de 70 $\mathrm{kWh} / \mathrm{m}^{2}$ que la bibliografía considera para edificios de bajo consumo. Se incorpora a la misma Tabla el consumo del fluido durante el año del monitoreo experimental. Los valores se detallan en $\mathrm{kWh} / \mathrm{m}^{2}$ y $\mathrm{kWh} / \mathrm{m}^{2} /$ día para poder comparar con las viviendas de referencia monitoreadas. El promedio de consumo diario de energía por metro cuadrado de superficie calefaccionada para las viviendas extrapoladas es de $0.95 \mathrm{kWh} / \mathrm{m}^{2} /$ día, valor muy cercano al registro medido de las viviendas monitoreadas. Es posible que la temperatura promedio interior en estas viviendas esté dentro de los valores medios en $\mathrm{C} 3$ y $\mathrm{C} 4\left(16.0\right.$ y $\left.17.9^{\circ} \mathrm{C}\right)$.

Figura 12 - Mosaicos urbanos en Villa del Busto y localización de viviendas de referencia
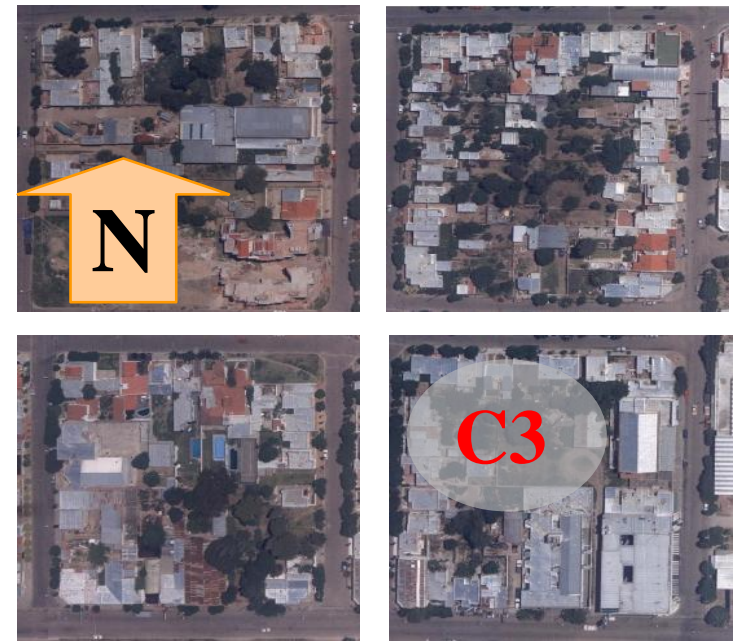
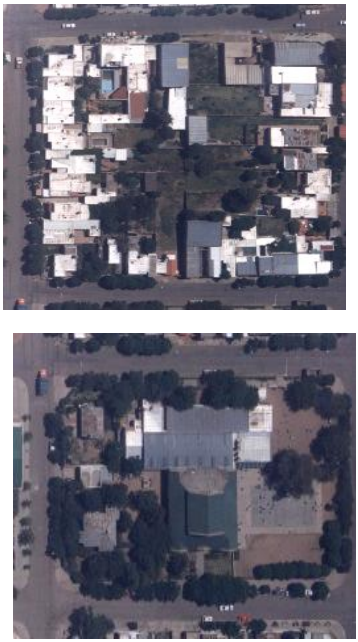
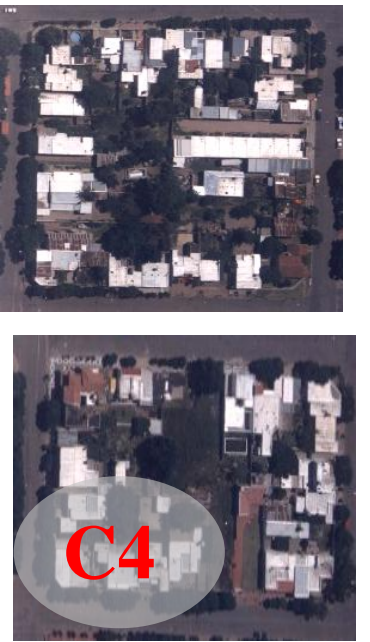

Fuente: Filippín y Flores Larsen (2012).

Tabla 4 - Consumo anual y bimestral de gas natural en $\mathrm{m}^{3}$ de las viviendas monitoreadas

\begin{tabular}{|c|c|c|c|c|c|c|c|c|c|c|}
\hline \multirow{4}{*}{ 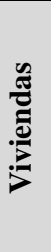 } & \multicolumn{6}{|c|}{$2000-2009$} & \multirow{2}{*}{\multicolumn{3}{|c|}{ Julio-Agosto 2010}} & \multirow{3}{*}{$\begin{array}{c}\text { julio } 2010 \\
\text { Calefacci- } \\
\text { ón }\end{array}$} \\
\hline & \multicolumn{3}{|c|}{ Año } & \multicolumn{3}{|c|}{ Julio-Agosto } & & & & \\
\hline & \multirow{2}{*}{$\begin{array}{c}\mathrm{kWh} \\
{[1]}\end{array}$} & \multicolumn{2}{|c|}{$\begin{array}{c}\text { Calefacción } 67 \% \text { de } \\
{[1]}\end{array}$} & \multirow{2}{*}{$\mathrm{m}^{3}[2]$} & \multirow{2}{*}{$\begin{array}{c}\text { julio [3] } \\
59.2 \% \text { de [2] } \\
\mathrm{m}^{3}\end{array}$} & \multirow{2}{*}{$\begin{array}{c}\text { Calefacción } \\
75 \% \text { de [3] }\end{array}$} & \multirow{2}{*}{$\begin{array}{l}\mathrm{m}^{3} \\
{[4]}\end{array}$} & \multicolumn{2}{|c|}{ julio $59.2 \%$ de [4] } & \\
\hline & & $\mathrm{kWh}$ & $\mathrm{kWh} / \mathrm{m}^{2}$ & & & & & $\mathrm{kWh}$ & $\mathrm{kWh} / \mathrm{m}^{2}$ & $\begin{array}{c}\mathrm{kWh} / \mathrm{m}^{2} / \\
\text { día }\end{array}$ \\
\hline$\overline{C_{3}}$ & 11819.5 & 7919.0 & 113.1 & 451.4 & 267.2 & 37.2 & 335 & 1932.4 & 27.6 & 0.7 \\
\hline $\mathrm{C}_{4}$ & 13861.8 & 9287.4 & 125.5 & 524.5 & 310.5 & 40.9 & 550 & 3172.6 & 42.9 & 1.0 \\
\hline
\end{tabular}

Tabla 5 - Consumo de gas natural de viviendas tipo cajón en el mosaico urbano para el período comprendido entre los años 2000 y $2009\left(\mathrm{~m}^{3}\right)$

\begin{tabular}{|c|c|c|c|c|c|c|c|}
\hline \multirow[b]{2}{*}{ Vivienda } & \multirow[b]{2}{*}{ orientación } & \multicolumn{3}{|c|}{ Año } & \multicolumn{3}{|c|}{ Julio-Agosto } \\
\hline & & promedio & $\begin{array}{c}\text { desvío } \\
\text { standard } \\
\end{array}$ & $\mathbf{C V}$ & Promedio [2] & $\begin{array}{c}\text { desvío } \\
\text { standard } \\
\end{array}$ & $\mathbf{C V}$ \\
\hline 1 & $\mathrm{O}$ & 1897.1 & 289.5 & 15.3 & 701.3 & 187.7 & 26.8 \\
\hline 2 & S & 1614.2 & 240.7 & 14.9 & 611.4 & 126.7 & 20.7 \\
\hline 3 & $\mathrm{~N}$ & 1808.3 & 507.8 & 28.1 & 713.0 & 224.4 & 31.5 \\
\hline 4 & $\mathrm{E}$ & 1558.3 & 102.6 & 6.6 & 545.7 & 59.1 & 10.8 \\
\hline 5 & $\mathrm{O}$ & 1493.5 & 204.1 & 13.7 & 485.1 & 71.6 & 14.8 \\
\hline 6 & $\mathrm{O}$ & 1129.4 & 137.5 & 12.2 & 380.4 & 56.9 & 14.9 \\
\hline 7 & $\mathrm{O}$ & 1235.1 & 251.0 & 20.3 & 489.9 & 146.7 & 29.9 \\
\hline 8 & $\mathrm{E}$ & 1166.2 & 101.4 & 8.7 & 446.3 & 42.4 & 9.5 \\
\hline
\end{tabular}

Nota: ${ }^{*} \mathrm{CV}$ - coeficiente de variación.

262 Filippín, C.; Sipowicz, E.; Larsen, S. F. 
Tabla 6 - Consumo de gas natural anual y durante julio para el período 2000-2009 y valores invernales para $2010(\mathrm{kWh})$

\begin{tabular}{|c|c|c|c|c|c|c|c|c|c|}
\hline \multirow{4}{*}{$\begin{array}{l}\frac{\pi}{0} \\
\frac{0}{0} \\
\frac{\pi}{2}\end{array}$} & \multicolumn{5}{|c|}{ 2000-2009 } & \multirow{2}{*}{\multicolumn{2}{|c|}{ Julio-Agosto 2010}} & \multirow{2}{*}{\multicolumn{2}{|c|}{ Julio 2010}} \\
\hline & \multicolumn{3}{|c|}{ Año } & \multicolumn{2}{|c|}{$\begin{array}{c}\text { Julio } \\
\mathbf{5 9 . 2 \%} \text { de [Tabla 2] }\end{array}$} & & & & \\
\hline & \multirow[b]{2}{*}{$\mathrm{kWh}[1]$} & \multicolumn{2}{|c|}{$\begin{array}{c}\text { Calefacción } 67 \% \text { de } \\
{[1]}\end{array}$} & \multirow[b]{2}{*}{ kWh [3] } & \multirow{2}{*}{$\begin{array}{l}\text { Calefacción } \\
75 \% \text { de [3] } \\
\mathrm{kWh} / \mathrm{m}^{2}\end{array}$} & \multirow{2}{*}{$\mathrm{m}^{3}[4]$} & \multirow{2}{*}{$\begin{array}{c}\text { julio } 59.2 \% \\
\text { de }[4] \\
\mathbf{k W h}\end{array}$} & \multicolumn{2}{|c|}{$\begin{array}{c}\text { Calefacción } 75 \% \text { de } \\
{[4]}\end{array}$} \\
\hline & & $\mathrm{kWh}$ & $\mathrm{kWh} / \mathrm{m}^{2}$ & & & & & $\mathrm{kWh} / / \mathrm{m}^{2}$ & $\begin{array}{c}\mathrm{kWh} / / \mathrm{m}^{2} \\
/ \text { día }\end{array}$ \\
\hline 2 & 15728.8 & 10538.3 & 127.4 & 3526.8 & 32.0 & 790 & 4557.1 & 41.3 & 1.33 \\
\hline 3 & 17620.1 & 11805.5 & 98.4 & 4112.9 & 25.7 & 826 & 4764.7 & 29.8 & 0.96 \\
\hline 4 & 15184.1 & 10173.3 & 162.8 & 3147.8 & 37.8 & 688 & 3968.7 & 47.6 & 1.54 \\
\hline 5 & 14552.7 & 9750.3 & 70.6 & 2798.3 & 15.2 & 559 & 3224.6 & 17.5 & 0.56 \\
\hline
\end{tabular}

Dado los valores de consumo de energía en calefacción obtenidos es pertinente estudiar alternativas de mejoramiento térmico de la envolvente para disminuir las pérdidas de calor para minimizar el consumo energía garantizando al mismo tiempo las condiciones de confort. Se propone una intervención de tipo tecnológica. Acordando con (VERBEECK; HENS, 2005), se considera que la medida de mejoramiento más simple y económica, es aislar la cubierta. La Norma IRAM 11605 (INSTITUTO..., 1996) recomienda tres niveles: $\mathrm{A}, \mathrm{B}$ y $\mathrm{C}$ con un valor de $\mathrm{K}$ de $0.26,0.67$ y $1.00 \mathrm{~W} / \mathrm{m}^{2} \mathrm{~K}$, respectivamente. Para cuantificar el ahorro se toma como ejemplo la vivienda de referencia $\mathrm{C}_{4}$ con transmitancia térmica original del techo de $1.52 \mathrm{~W} / \mathrm{m}^{2} \mathrm{~K}$. A través del modelo de simulación Simedif bajo Windows (FLORES LARSEN; LESINO, 2001) se determina la carga de calefacción para una temperatura interior de termostato de $18^{\circ} \mathrm{C}$. Los resultados muestran que la vivienda de referencia con un techo mejorado térmicamente $(\mathrm{K}=0.48$ $\mathrm{W} / \mathrm{m}^{2} \mathrm{~K}$ ) tendría una carga de calefacción de 54.1 $\mathrm{kWh} /$ día. El consumo real medido en 2010 fue de $65.5 \mathrm{kWh}$ /día para una temperatura media interior de $17.7^{\circ} \mathrm{C}$ y una temperatura media exterior de $7.4^{\circ} \mathrm{C}$. El ahorro de energía en calefacción es del $17.4 \%$.

Una manzana de la unidad representativa en estudio tiene aproximadamente 40 viviendas. De acuerdo a la vivienda $\mathrm{C} 4 \mathrm{de}$ referencia, en julio se requieren diariamente $2620 \mathrm{kWh}$ para calefaccionar cada manzana. Para 30 días de calefacción y para las 100 manzanas del sector urbano en estudio, la demanda energética será de $7860000 \mathrm{kWh} / \mathrm{mes}\left(804714 \mathrm{~m}^{3}\right.$ de gas natural). Como se dijo anteriormente, la intervención tecnológica de la cubierta mediante el aumento de su resistencia térmica, permitiría un ahorro del
$17.4 \%$ en la demanda total de calefacción para el mes de Julio $\left(1.367 .640 \mathrm{kWh}=140.020 \mathrm{~m}^{3}\right.$ de gas natural $=323.306,18 \mathrm{Tn} \quad \mathrm{CO}_{2}$ ). Este ahorro de energía mensual, producto de la intervención tecnológica de 4000 viviendas, que los autores consideran auspicioso, permitiría calefaccionar en el mes de julio a 696 viviendas convencionales u 843 viviendas con intervención de mejoramiento de cubierta, equivalentes al 2,5\% del total de viviendas presentes en la ciudad de Santa Rosa, La Pampa según datos del Censo $2010^{4}$. Una forma gráfica de visualizar el ahorro en emisiones de $\mathrm{CO}_{2}$, es considerar que si, $1 \mathrm{Tn}$ de $\mathrm{CO}_{2}$ es suficiente para llenar un balón de $10 \mathrm{~m}$ de diámetro, el ahorro en las emisiones de $\mathrm{CO}_{2}$ producto de la intervención tecnológica podría ser representado como una esfera de $3233 \mathrm{~km}$ de diámetro.

Filippín, Flores Larsen e Mercado (2011) estimaron un ahorro del $18 \%$ en la carga de refrigeración para la misma situación (272160 $\mathrm{kWh}$ ). El ahorro de energía en calefacción y aire acondicionado para los dos meses más críticos en la región en estudio, y en 100 manzanas de baja densidad de edificación con intervención tecnológica a través de medidas de conservación (aislación térmica en cubierta) sería de 1639800 $\mathrm{kWh}$, valor que determina una importante reducción de la emisión de $\mathrm{CO}_{2}$. Este valor total de la energía ahorrada muestra la mayor participación en el sector residencial de la energía requerida en calefacción en la región en estudio (83.4\%). En próximos trabajo se evaluará el costo de la intervención y la tasa de retorno de la intervención.

${ }^{4}$ Según el Censo 2010, Santa Rosa- La Pampa-, presenta 41.546 viviendas, de las cuales el $80 \%$ es de carácter unifamiliar. Lo que equivale a un total de 33.237 viviendas. 


\section{Conclusiones}

El trabajo permitió analizar el comportamiento térmico y energético de cuatro viviendas compactas ubicadas en barrios de baja densidad, con predominancia de edificación de una sola planta con una tipología similar a las estudiadas. Las viviendas son másicas, entre medianeras, con distinta orientación. Las condiciones climáticas del período de medición fueron muy rigurosas. Se destaca que los usuarios de las viviendas medidas han adoptado estrategias de climatización natural: apertura de cortinas de enrollar en horas de mayor insolación y cierre de las mismas hacia el ocaso. Se analizó el comportamiento de la temperatura interior, el consumo de energía durante el mismo período de medición y las condiciones de confort. En una segunda etapa se tomaron dos de las cuatro viviendas, y se realizó una evaluación energética en una unidad representativa de un área homogénea (barrio en el cuál se localizan las viviendas estudiadas).

La temperatura promedio en las viviendas osciló entre 16 y $22^{\circ} \mathrm{C} \mathrm{El} \mathrm{consumo} \mathrm{de} \mathrm{energía} \mathrm{para}$ calefacción de las viviendas compactas entre medianeras es un $50 \%$ menor al volumen consumido por la vivienda social unifamiliar apareada en la misma región en estudio (208.9 $\mathrm{kWh} / \mathrm{m}^{2}$ ), acordando con el trabajo de (SANTAMOURIS et al., 2007) quienes dicen que el consumo de energía en calefacción y electricidad es mucho más alto en los grupos de menores ingresos por la calidad energética pobre de la envolvente de la vivienda.

Si fuera posible la intervención tecnológica de la cubierta el ahorro de energía en calefacción sería altamente satisfactorio. Se acuerda con (VERBEECK; HENS, 2005) quienes consideran que la implementación de medidas de mejoramiento energético depende de la disponibilidad de presupuesto para las mejoras, que pueden ser realizadas al mismo tiempo o por etapas en forma independiente una de otra. (DASCALAKI et al., 2010), afirman en su trabajo que el mejoramiento de la resistencia térmica del techo se requiere en todos los edificios, y debe ser implementada en la rutina de rehabilitación de los edificios.

El uso de diagramas bioclimáticos en la etapa de diseño facilitaría la toma de decisiones, diagramas que recomiendan para la región en estudio para invierno el uso de masa térmica y captación de radiación solar pasiva para disminuir el consumo energético. Se destaca hacia la izquierda del diagrama psicométrico, que el recurso solar disponible sobre superficie vertical para la región bioambiental IIIa estudiada no es suficiente por lo que se necesitaría recurrir al calor auxiliar. Situación observada en dos de los casos estudiados, donde aun con áreas solares colectoras al norte consumen gas natural para alcanzar las condiciones de confort. Edificios bioclimáticos construidos y evaluados en la región ratifican que con un buen diseño de solarización y conservación es posible disminuir el consumo de energía convencional manteniendo el confort de las viviendas. El diseño arquitectónico de invierno amerita considerar las recomendaciones que surgen de los diagramas bioclimáticos y del análisis climático detallado del lugar en estudio.

El panorama energético de Argentina, la posibilidad de revisar Normativas y Códigos de Edificación, el incremento en la compra de equipos de aire acondicionado, la tendencia del crecimiento de la construcción de viviendas en la región en estudio, el proceso de etiquetado de la edificación, entre otros aspectos, ameritan un análisis de la información de las características del stock de edificios y de su performance energética. En acuerdo con (DASCALAKI, et al., 2010) la creación de un protocolo de monitoreo armonizado de datos es imperativa.

\section{Referencias}

\section{ALLCOTT; HUNT; MULLAINATHAN}

SENDHIL. Behavior and Energy Policy. Science, v. 327, n. 5970, p. 1204-1205, mar. 2010.

AULICIEMS, A.; SZOKOLAY, S. Thermal Comfort, Design Tools and Techniques. In: PLEA Notes 3. $2^{\text {nd }}$ ed. 2007.

BALLARINI, I.; CORRADO, V. Application of Energy Rating Methods to the Existing Building Stock: analysis of some residential buildings in Turin. Energy and Buildings, v. 41, n. 11, p. 790800, 2009.

BEHLING, S.; BEHLING, S. Sol Power: la evolución de la arquitectura sostenible. Barcelona: Ediciones G. Gili, 2002.

BRITO, G. A.; MAUR, I. Buenos Aires 19201940: una modernidad silenciosa. Disponíble en: <https://www.google.com.ar/url?sa=t\&rct=j\&q=\& esrc $=$ s \& source $=$ web $\& c d=7 \&$ ved $=0$ CEIQFjAG\&ur l=http $\% 3 \mathrm{~A} \% 2 \mathrm{~F} \% 2 \mathrm{Fwww}$.rafaellopezrangel.com\% 2FReflexiones \%2520sobre\%25201a\%2520arquitec tura $\% 2520 y \% 2520 \mathrm{el} \% 2520$ urbanismo\%2520latin oamericanos\%2FDesign\%2Farchivos\%2520texto \%2FBuenos\%2520Aires.doc\&ei=fZgbUoygLovm 8wTHrYHYCQ\&usg=AFQjCNF103VP0uDo797iS PQd5nQ5FT8bNw\&sig2=izzjbW2wvR8dacvsOQ KDug\&cad=rja>. Acceso en: 29 dec. 2013. 
CAMUZZI GAS PAMPEANA. Informe Anual' 08. Argentina, 2009.

CENTRO COMPLUTENSE DE ESTUDIOS E INFORMACIÓN MEDIOAMBIENTAL. Cambio Global España 2020/50: energía, economía y Sociedad. Madri, 2010. p. 60.

COVAS, M. R.; TOURN, M.; PEREZ, E. Ciudad de Santa Rosa: geografía histórica. Santa Rosa: Universidad Nacional de La Pampa, 1986.

DASCALAKI, E. et al. Data Collection and Analysis of the Building Stock and Its Energy Performance: an example for Hellenic buildings. Energy and Buildings, v. 42, n. 8, p. 1231-1237, 2010.

DIXIT, M. K. et al. Identification of Parameters For Embodied Energy Measurement: a literature review. Energy and Buildings, v. 42, n. 8, p. 1238-1247, 2010.

FILIPPÍN, C. et al. Response of Conventional and Energy-Saving Buildings to Design and Human Dependent Factors. Solar Energy, v. 78, n. 3, p. 455-470, 2005.

FILIPPÍN, C.; FLORES LARSEN, S. Analysis of Energy Consumption Patterns in Multi-Family Housing in a Moderate Cold Climate. Energy Policy, v. 37, n. 9, p. 3489-3501, 2009.

FILIPPÍN, C.; FLORES LARSEN, S. Summer Thermal Behavior of Compact Single Family Housing in a Temperate Climate in Argentina. Renewable and Sustainable Energy Reviews, v. 16, p. 3439-3455, 2012.

FILIPPÍN, C.; FLORES LARSEN, S.; MERCADO, V. Winter Energy Behavior in MultiFamily Block Buildings in a Temperate-Cold Climate in Argentina. Renewable and Sustainable Energy Reviews, v. 15, n. 1, p. 203219, 2011.

FLORES LARSEN, S.; LESINO, G. A New Code For the Hour-by-Hour Thermal Behavior Simulation of Buildings. In: INTERNATIONAL IBPSA CONFERENCE ON BUILDING SIMULATION, 7., Río de Janeiro, 2001. Proceedings... Rio de Janeiro, 2001. p. 75-82.

FUNDACIÓN BARILOCHE. Inventario Nacional de la República Argentina: de fuentes de emisiones y absorciones de gases de efecto invernadero, no controlados por el protocolo de Montreal. Fundación Bariloche, 2005.
GANEM, C.; ESTEVES, A.; COCH, H. Rehabilitación Ambiental de la Tipología de Medio Patio: parte 1: diagnóstico cualitativo y cuantitativo del confort térmico. Avances en Energías Renovables y Medio Ambiente, v. 10, n. 5, p. 49-55, 2006.

GONZÁLEZ, A. D. et al. Residential Energy Use in One-Family Households With Natural Gas Provision in a City of the Patagonian Andean Region. Energy Policy, v. 35, p. 2141-2150, 2007.

\section{GONZÁLEZ PODESTÁ, A. Habitar Buenos}

Aires: las manzanas, los lotes y la casas.

Disponíble en:

<http://pt.scribd.com/doc/97128316/Casa-ChorizoAquilino-Podesta>. Acceso en: 21 dez. 2013.

GROSSI GALLEGOS, H.; RIGHINI, R. Atlas de Energía Solar de la República Argentina. Buenos Aires: Universidad de Luján, 2007.

HERNÁNDEZ, F. Resultados del Monitoreo Térmico de Una Vivienda Construida en la Ciudad de Salta y Su Simulación Detallada Mediante Simedif. Avances en Energías Renovables y Medio Ambiente, v. 10, n. 3, p. 39-46, 2006.

INSTITUTO NACIONAL DE ESTADÍSTICA Y CENSOS. [Estadísticas]. 2006. Disponible en: <http://www.estadisticalapampa.gov.ar/index.php? option=com_content\&task=view\&id=134\&Itemid =58>. Acceso en: 19 nov. 2013.

INSTITUTO PARA LA DIVERSIFICACIÓN Y EL AHORRO DE LA ENERGÍA. Guía Práctica de la Energía. Consumo Eficiente y

Responsable. $3^{\mathrm{a}}$ ed. Madrid, 2010. p. 179.

Disponible en:

<http://www.idae.es/guiaenergia/guiapracticacomp leta.pdf $>$. Acceso en: 20 mayo 2013.

INTERGOVERNMENTAL PANEL ON CLIMATE CHANGE. 5 Working Group III. In: ASSESSMENT REPORT, 5., 2007.

Proceedings... New York, 2007. cap. 6, p. 1-91.

INSTITUTO ARGENTINO DE

NORMALIZACIÓN Y CERTIFICACIÓN.

IRAM 11605: acondicionamiento térmico de edificios: condiciones de habitabilidad en edificios: valores máximos de transmitancia térmica en cerramientos opacos. Buenos Aires, 1996.

INSTITUTO ARGENTINO DE

NORMALIZACIÓN Y CERTIFICACIÓN.

IRAM 11603: clasificación bioambiental de la República Argentina. Buenos Aires, 1996.

LIU, J.; ZHANG, T.; ZHAI, Z. Considering Building Energy From Environmental Perspective. Energy and Buildings, v. 42, n. 1, 2010. 
MERCADO, M. V. et al. Evaluación TérmicoEnergético y Cualitativa de Condiciones Ambientales de Una Vivienda Social de la Ciudad de Mendoza: condiciones reales de uso y estrategias de mejoramiento térmico-energético bioclimático. Avances en Energías Renovables y Medio Ambiente, v. 12, n. 05, p. 73-80, 2008.

MITCHELL, J.; ACOSTA, P. Evaluación Comparativa de Tipologías de Viviendas Sociales en la Provincia de Mendoza. Avances en Energías Renovables y Medio Ambiente, v. 13, n. 5, p. 161-168, 2009.

MOLAS, L. et al. Auditoría Térmica y Variables del Confort: caso de una vivienda del Instituto Provincial de la Vivienda, Ciudad de Catamarca. Avances en Energías Renovables y Medio Ambiente, v. 12, p. 121-128, 2008.

PEETERS, L. et al. Thermal Comfort in Residential Buildings: comfort values and scales for building energy simulation. Applied Energy, v. 86, n. 5, p. 772-780, 2009.

RATTI, C.; BAKER, N.; STEAMERS, K. Energy Consumption and Urban Texture. Energy and Buildings, v. 37, n. 7, p. 762-776, 2005.

RATTI, C.; RAYDAN, D.; STEAMERS, K. Building Form and Environmental Performance: archetypes, analysis and an arid climate. Energy and Buildings, v. 35, p. 3-14, 2003.

RE, M. G.; BLASCO LUCAS, I. Monitoreo Higrotérmico-Energético-Lumínico de Invierno en Departamentos Ubicados en las Ciudades de San Juan y La Plata. Avances en Energías

Renovables y Medio Ambiente, v. 12, 2008.

ROSENFELD, E.; CZAJKOWSKI, J. Catálogo de Tipologías de Viviendas Urbanas en el Área Metropolitana de Buenos Aires: su funcionamiento energético y bioclimático. Instituto de Estudios del Hábitat, 1992.

SALVETTI, M. B.; CZAJKOWSKI, J.; GÓMEZ, A. F. Análisis del Comportamiento EnergéticoAmbiental en Torre de Viviendas en La Plata.

Avances en Energías Renovables y Medio Ambiente, Impreso en la Argentina, v. 13, n. 05, p. 127-134, 2009.

SALVETTI, M. B.; CZAJKOWSKI, J.; GÓMEZ, A. F. Ahorro de Energía en Refrigeración de Edificios Para Oficinas: propuesta de indicadores de eficiencia y valores admisibles. Avances en Energías Renovables y Medio Ambiente, v. 14, p. $17-24,2010$.
SANTAMOURIS, M. et al. On the Relation Between the Energy and social Characteristics of the Residential Sector. Energy and Buildings, v. 39, n. 8, p. 893-905, 2007.

SARTORI, I.; HESTNES, A.G. Energy Use in the Life Cycle of Conventional and Low-Energy Buildings: a review article. Energy and Buildings, v. 39, n. 3, p. 249-257, mar. 2007.

SERRA FLORENSA, R.; COCH ROURA, H. Arquitectura y Energía Natural. Barcelona: Edicions UPC, 1995.

SERVICIO METEREOLOGICO NACIONAL. Fuerza Aérea. Periodo: 1990-1999. Argentina, 2000.

SUBSECRETARÍA DE PLANEAMIENTO. La

Pampa: análisis de la realidad. La Pampa: Gobierno de La Pampa, 1994.

SULAIMAN, H.; BLASCO LUCAS, I.; FILIPPÍN, C. Incidencia del Usuario en el Comportamiento Higrotérmico Estival de Una Vivienda Convencional en San Juan. Avances en Energías Renovables y Medio Ambiente, v. 13, n. 5, p. 53-60, 2009.

ÜRGE-VORSATZ, D.; NOVIKOVA, A. Energy Efficiency and the Kyoto Protocol in an Enlarged EU: will they make a difference? In: IMPROVING ENERGY EFFICIENCY IN NEW EUROPE, Oxford, 2006. Proceedings... Oxford, 2006.

VERA BOTI, A. Apuntes Rápidos de Alfredo Vera Boti Para Un Estudio Sobre Modelos, Tipos y Tipologia. Disponíble en: <http://www.aq.upm.es/Departamentos/Composici on/webcompo/Master/Modulo\%20B/Maure/3.1. Modelos, \%20tipos\%20y\%20tipologia.pdf>. Acceso en: 29 dec. 2013.

VERBEECK, G.; HENS, H. Energy Saving in Retrofitted Dwellings: economically viable? Energy and Buildings, v. 37, n. 7, p. 747-754, 2005.

VIEGAS, G. Evaluación del Potencial Energético e Intervenciones de Mejoramiento del Entorno Edilicio en Áreas Urbanas de Media y Baja Consolidación: la ciudad de La Plata como caso de estudio. Tesis (Doctoral) Universidad Nacional de Salta, Salta, Argentina, 2010 . 


\section{Celina Filippín}

Consejo Nacional de Investigaciones Científicas y Técnicas | Avda. Spinetto, 785 | Santa Rosa - La Pampa - Argentina | C.P.6300 Tel.: +(54) 2954 434-222 | E-mail: cfilippin@cpenet.com.ar

\section{Eugenia Sipowicz}

Centro Experimental de Viviendas Económicas | Consejo Nacional de Investigaciones Científicas y Técnicas | Igualdad, 3585 | Córdoba Capital - Argentina | C.P. X5003BHG | Tel.: +(54) 351 489-4442 | E-mail: esipowicz@ceve.org.ar

Silvana Flores Larsen

Instituto de Investigaciones en Energías No Convencionales | Consejo Nacional de Investigaciones Científicas y Técnicas | Universidad Nacional de Salta | Avda. Bolivia, 5150 | Salta - Argentina | C.P. 4400 | Tel.: +(54) 387 425-5578 | E-mail: sfloreslarsen@gmail.com.ar

\section{Revista Ambiente Construído}

Associação Nacional de Tecnologia do Ambiente Construído

Av. Osvaldo Aranha, $99-3^{\circ}$ andar, Centro

Porto Alegre - RS - Brasil

CEP $90035-190$

Telefone: +55 (51) 3308-4084

Fax: +55 (51) 3308-4054

www.seer.ufrgs.br/ambienteconstruido

E-mail: ambienteconstruido@ufrgs.br 